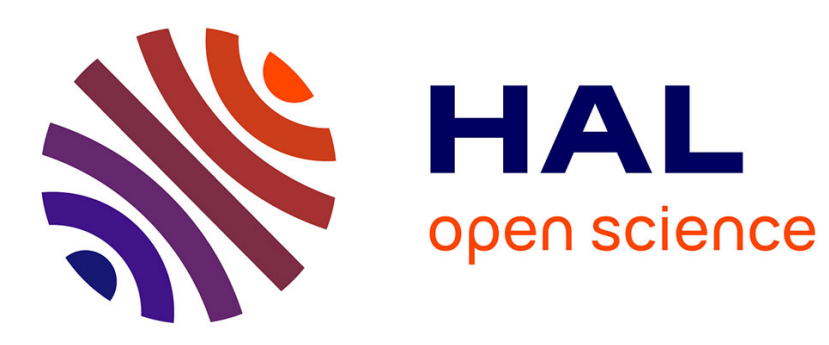

\title{
Enrichment of alpha-linolenic acid in rodent diet reduced oxidative stress and inflammation during myocardial infarction
}

Kin Sum Leung, Jean-Marie Galano, Camille Oger, Thierry Durand, Jetty

Chung-Yung Lee

\section{To cite this version:}

Kin Sum Leung, Jean-Marie Galano, Camille Oger, Thierry Durand, Jetty Chung-Yung Lee. Enrichment of alpha-linolenic acid in rodent diet reduced oxidative stress and inflammation during myocardial infarction. Free Radical Biology and Medicine, 2021, 162, pp.53-64. 10.1016/j.freeradbiomed.2020.11.025 . hal-03115368

\author{
HAL Id: hal-03115368 \\ https://hal.science/hal-03115368
}

Submitted on 19 Jan 2021

HAL is a multi-disciplinary open access archive for the deposit and dissemination of scientific research documents, whether they are published or not. The documents may come from teaching and research institutions in France or abroad, or from public or private research centers.
L'archive ouverte pluridisciplinaire HAL, est destinée au dépôt et à la diffusion de documents scientifiques de niveau recherche, publiés ou non, émanant des établissements d'enseignement et de recherche français ou étrangers, des laboratoires publics ou privés. 


\title{
Enrichment of alpha-linolenic acid in rodent diet reduced oxidative stress and inflammation during myocardial infarction
}

\author{
Kin Sum Leung ${ }^{\mathrm{a}}$, Jean-Marie Galano ${ }^{\mathrm{b}}$, Camille Oger ${ }^{\mathrm{b}}$, Thierry Durand ${ }^{\mathrm{b}}$, \\ Jetty Chung-Yung Lee ${ }^{a, *}$ \\ a School of Biological Sciences, The University of Hong Kong, Hong Kong, SAR, China \\ ${ }^{\mathrm{b}}$ Institut des Biomolécules Max Mousseron, UMR 5247 CNRS, ENSCM, Université de Montpellier, France
}

\begin{abstract}
Myocardial infarction (MI) is an irreversible event caused by cardiac ischemia and may be fatal. Studies reported that increased intake of n-3 polyunsaturated fatty acids (PUFA) namely, eicosapentaenoic acid and docosahexaenoic acid reduce the risk of cardiovascular disease and lower the incidence of MI. Nonetheless, the cardioprotective effect of plant n-3-PUFA such as $\alpha$-linolenic acid (ALA) in the diet is not conclusive. In this study, Sprague Dawley rats were supplemented with isocaloric diets enriched with ALA rich flaxseed (FS) and flaxseed oil (FSO), and normal chow (Control) for 4 weeks. MI was induced by isoproterenol (ISO) injection. Results showed that all ALA-enriched diets displayed cardioprotection against MI. The heart to body weight ratio, plasma LDH activity and plasma cTnI were reduced compared to ISO and was prominent in FS diet. ALA and EPA were up-regulated in both tissues and plasma by ALA-diets compared to Control and remained higher than ISO groups. Notably, LOX-mediated HETEs decreased whereas LOX-mediated HDHAs were elevated in both tissues and plasma of ALA-enriched diets compared to ISO. In addition, non-enzymatic oxidized products from arachidonic acid including $15-\mathrm{F}_{2 \mathrm{t}}$-IsoP were reduced in both tissues and plasma of MI rats supplemented with ALA-enriched diets while those from n-3 PUFAs including $\mathrm{F}_{4}$-NeuroPs, PhytoPs and PhytoFs were elevated compared to control. ALA-enriched diets particularly flaxseed reduced gene expressions of inflammatory cytokines namely IL-1 $\beta$, IL-6 and TNF $\alpha$ and prevented the down regulation of antioxidant catalase in the heart tissues. In conclusion ALAenriched diets potentially exerted cardioprotection through the regulation of anti-inflammatory and antioxidative mediators from n-3 PUFA autooxidation.
\end{abstract}

Keywords:

$\alpha$-Linolenic acid

Polyunsaturated fatty acids

Lipid oxidation

Isoprostanes

Phytoprostanes

Myocardial infarction

\section{Introduction}

Myocardial infarction (MI) caused by cardiac ischemia is an irreversible process leading to myocardial cells death. Several studies revealed that increased intake of $n-3$ polyunsaturated fatty acid (PUFA), especially from marine-based food source like eicosapentaenoic acid (EPA) and docosahexaenoic acid (DHA) reduced the risk of cardiovascular disease and lowered the incidence of MI [1,2]. EPA and DHA are also found to reduce plasma triglyceride levels [3], resting heart rate and blood pressure [4], thrombotic eicosanoids production [5], inflammatory cytokine production [6], and the risk of arrhythmia by enhancing myocardial efficiency and oxygen demand for the myocardium [7].
However, the cardioprotective effect of n-3 PUFA from plant food source namely $\alpha$-linolenic acid (ALA) is not that profound. Although few studies reported increased consumption of ALA rich diet is associated with lower CVD and MI risk, the evidence was not conclusive and the association between ALA and CVD risk reduction was not as strong as those in EPA and DHA [8,9]. Some researchers suggested that the cardioprotective properties of ALA were due to increased conversion of ALA to EPA and DHA via ALA-rich diet consumption while others suggested that ALA has its own health benefits and thus, essential to consume all types of n-3 PUFA in the diet to have a full protection [10].

PUFA undergoes non-enzymatic lipid peroxidation and in the case of ALA, it generates phytoprostanes (PhytoPs) and phytofurans (PhytoFs).

Abbreviations: AA, Arachidonic acid; ALA, $\alpha$-linolenic acid; cTn, cardiac troponin; DHA, docosahexaenoic acid; EPA, eicosapentaenoic acid; IsoP, isoprostane;

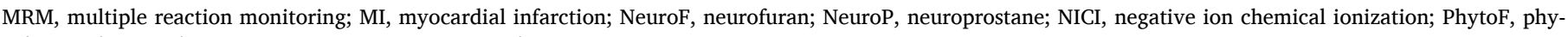
tofuran; PhytoP, phytoprostane; SD rat, Sprague Dawley rat.

* Corresponding author. School of Biological Sciences The University of Hong Kong, Pokfulam Road, Hong Kong, SAR, China.

E-mail address: jettylee@hku.hk (J.C.-Y. Lee). 
However, their biological functions in in vivo is much less known compared to $\mathrm{F}_{3}$-IsoPs and $\mathrm{F}_{4}$-NeuroPs from EPA and DHA respectively. PhytoPs are mainly found in higher plant and an elevation is associated with increased oxidative stress of plants. However it is suggested that certain types of PhytoPs are biologically active in plant and protect against oxidative stress damage. For instance, $\mathrm{A}_{1}$-and $\mathrm{B}_{1}$-PhytoPs helped to detoxify xenobiotics and increase gene expressions in plant related to cytoprotective responses [11,12]. Nonetheless, the effects of PhytoPs and PhytoFs in mammalian systems is not fully explored. Insofar, it was only found that oils with high ALA content could increase the level of PhytoPs in plasma after ingestion [13], suggesting them to be generated and metabolized in vivo through autooxidation process. In addition, the effects of PhytoPs has been elucidated in mammalian cell models where $\mathrm{E}_{1}$-PhytoP had immunomodulatory activity, modulated dendritic cell functions and stimulated type 2 immune response [14], $\mathrm{B}_{1}$-PhytoPs protected animal cells against oxidative stress injury through PPAR- $\gamma$ activation and prevented cell death [15] and recently, it was discovered that glycerol-bound PhytoPs are responsible in the immediate effector phase of allergic inflammation [16]. It is evident that PhytoPs are biologically active in both plant and animal systems, therefore we postulate that PhytoPs and/or PhytoFs may take part in cardioprotection when ALA-rich foods are regularly consumed.

In this study, cardioprotective effect of ALA was investigated in rodents. Sprague Dawley rats were fed with normal chow diet and ALAdiets supplemented by either flaxseed (FS) or flaxseed oil (FSO). Both are known to be rich in ALA but FSO lacks dietary fiber, lignans and proteins, and some antioxidant phenolic compounds since they are removed in the defatted flaxseed meal as 'by-product' during extraction [17]. Feeding the rats with either diets can distinguish if pure ALA (FSO) indeed have cardioproctective effect or ALA with other bioactive components e.g. phenolic compounds that have antioxidant property (FS) contribute to this protection.

Myocardial infarction was induced by using isoproterenol (ISO). It is a potent $\beta$-adrenergic receptor stimulator which increase the heart rate and contractility, and cause vasodilation resulting in increased cardiac output and reduction of blood pressure [18]. It is often used in treating symptomatic bradycardia or heart block, but high dose of ISO can provoke MI like damages in the heart tissues [19]. The aim of this study is to evaluate the effect of ALA supplementation on lipid profile in liver and heart tissues, and in circulation, and its potential protective effect against MI.

\section{Experimental section}

\subsection{Standards and reagents}

All solvents used in the experiments were either analytical reagent grade or HPLC grade. All PUFA and oxidized lipid product standards, and heavy labeled internal standards were purchased from Cayman Chemical Co. (Ann Arbor, MI, USA) or synthesized by Institut des Biomolécules Max Mousseron (IBMM, Montpellier, France).

\subsection{Animals}

A total of 24 male Sprague Dawley (SD) rats of similar body weight $(350 \pm 50 \mathrm{~g})$ and age ( 8 weeks old) were used in this study. All rats were separated into groups of two in a solid-bottom polycarbonate cage with autoclaved hardwood bedding and freed to access deionized and reverse-osmosis-treated water, and sterile rodent chow ad libitum. The animals were kept in 12-h light and dark cycles and $20-25{ }^{\circ} \mathrm{C}$ with $35-70 \%$ relative humidity. Body weight, feed intake and signs of abnormality were monitored throughout the study. The animal experiments commenced after one week of acclimatization and were complied with the local institutional ethical guidelines (Committee on the Use of Live Animals in Teaching and Research No. 3733-15 and 3804-15, The University of Hong Kong) and license of Department of Health, Hong
Kong SAR Government.

\subsection{Experiment design}

SD rats were randomly assigned into one of the six treatment groups ( $\mathrm{n}=8$ per group): control (standard chow diet), flaxseed-enriched diet (FS, 4.6\% ground flaxseed, $\mathrm{w} / \mathrm{w}$ ) and flaxseed oil-enriched diet (FSO, $1.9 \%$ flaxseed oil, w/w) groups. At the end of the supplementation period, half of the rats ( $\mathrm{n}=4$ per group) were induced with MI using isoproterenol (ISO). The diets used in this study were isocaloric $(18 \%$ kcal protein, $65 \% \mathrm{kcal}$ carbohydrate and $16 \% \mathrm{kcal}$ fat) and have similar level of ALA content (10\%). All the diets were customized by Research Diet using Open Standard Diet D11112221 (Research Diets, New Brunswick, USA) where the composition details are shown in supplementary information, Table S1. The rats were fed with corresponding diets for 28 days. After $12 \mathrm{~h}$ fasting, half of the rats in control, FS and FSO groups received subcutaneous injection of ISO $(100 \mu \mathrm{g} / \mathrm{kg})$. After $12 \mathrm{~h}$ post-injection, blood samples were collected by cardiac puncture for plasma extraction from the animals under anesthesia. Then, the animals were sacrificed via cervical dislocation. Liver and heart tissues were immediately harvested. The whole heart was washed with PBS containing $0.005 \%(\mathrm{w} / \mathrm{v})$ BHT and $0.005 \%(\mathrm{w} / \mathrm{v})$ indomethacin, dried by paper blot, weighed, and stored at $-80{ }^{\circ} \mathrm{C}$.

The dose of ISO used in this study was lower than recent literature reports [20-22] as the concentration suggested ( $85 \mathrm{mg} / \mathrm{kg}$, subcutaneously injected for two consecutive days after treatments) led to $100 \%$ death rate after applying the first $85 \mathrm{mg} / \mathrm{kg}$ ISO injection to the SD rats. The high death rate in our experiment is likely due to the weight of the male SD rats after each diet treatments, as it reached approximately 500 $\mathrm{g}$ after 4 weeks feeding. According to Balazs et al., the median lethal dose (LD50) of ISO in male SD rat weighting 300-500 $\mathrm{g}$ is 300-600 $\mu \mathrm{g} / \mathrm{kg}$ [23]. Therefore, the ISO dose used in our study was reduced to $100 \mu \mathrm{g} / \mathrm{kg}$ according to Balazs et al. study, which is sufficient to induce MI like damage in heavy male SD rats (SD rat weighting 300-500 g).

\subsection{Total phenolic capacity analysis}

One gram of grounded FS sample or FSO was extracted with $100 \mathrm{~mL}$ methanol at $25{ }^{\circ} \mathrm{C}$ for $6 \mathrm{~h}$ with constant agitation using orbital shaker. Afterwards the mixture was centrifuged at $3000 \mathrm{rpm}$ for $10 \mathrm{~min}$. The supernatant was collected, and the residue was extracted again with methanol to increase the yield. The supernatants from the same sample were combined and dried completely under nitrogen. The dried samples were weighed and resuspended in methanol in the ratio of $1 \mathrm{~g}$ sample: $10 \mathrm{~mL}$ solvent [24].

Total phenolic capacity of the samples was measured by FolinCiocalteu Assay according to Ainsworth et al. method with slight modification [25]. In brief, gallic acid was diluted in different concentration (from $50 \mu \mathrm{M}$ to $2.5 \mathrm{mM}$ ) in $95 \%$ methanol and used as standard for the calibration curve. A volume of $100 \mu \mathrm{L}$ diluted Folin-Ciocalteu phenol reagent (1:10, reagent: distilled water) and $800 \mu \mathrm{L}$ of $700 \mathrm{mM}$ sodium carbonate solution were added to $200 \mu \mathrm{L}$ of standards, samples or blank. The absorbances of the samples was taken at $765 \mathrm{~nm}$ after incubated at room temperature for $2 \mathrm{~h}$. All determinants were carried out in triplicates.

\subsection{Plasma lactate dehydrogenase ( $L D H)$ activity measurement by $L D H$ assay}

LDH activity of the plasma samples was estimated by using commercially available assay kit (ab102526, Abcam. USA). In brief, 50 $\mu \mathrm{l}$ of 100 times diluted plasma samples were added into a 96 well plate and mixed well with $50 \mu \mathrm{l}$ of the reaction mix. Sample absorbance was measured at $450 \mathrm{~nm}$ using Multiskan ${ }^{\mathrm{TM}}$ GO Microplate Spectrophotometer (Thermo Scientific, USA) set to kinetic mode and determined every $3 \mathrm{~min}$ for $60 \mathrm{~min}$ at $37^{\circ} \mathrm{C}$ in the dark. LDH activity of the samples 
were calculated according to the manufacturers' instructions.

\subsection{Plasma cardiac troponin I ( $c T n I)$ measurement by indirect ELISA method}

Plasma cTnI level was measured using indirect ELISA method (Abcam indirect ELISA protocol, USA). In brief, the plasma samples were diluted 100 times with $100 \mathrm{mM}$ bicarbonate coating buffer, layered in each well of the 96 well microtiter plate and incubated at $4{ }^{\circ} \mathrm{C}$ overnight. After removing the coating solution and washing the wells with $200 \mu \mathrm{l}$ PBS three times, the coated wells were blocked by incubating with 200 $\mu \mathrm{l} 5 \%$ non-fat dry milk at $4{ }^{\circ} \mathrm{C}$ overnight. Diluted rabbit polyclonal (x 1000) cardiac troponin I primary antibody (ab47003, Abcam, USA) was added to each well and incubated at $4{ }^{\circ} \mathrm{C}$ overnight. Thereafter, $100 \mu \mathrm{l}$ of 5000 times diluted goat anti-rabbit IgG H\&L (HRP) secondary antibody (ab97051, Abcam. USA) was added and incubated in room temperature for 1-2 h. Finally, horseradish peroxidase (HRP) chromogens was detected by reacting with 2,2'-azino-di-[3-ethyl-benzothiazoline-6-sulfonic acid] diammonium salt (ABTS) and the end products were measured at $416 \mathrm{~nm}$ using Multiskan ${ }^{\mathrm{TM}} \mathrm{GO}$ Microplate Spectrophotometer (Thermo Scientific, USA). Rat cTnI protein (7010, Life Diagnostics, WC, USA) was used for the standard curve.

\subsection{Lipid extraction of the biological samples}

Total lipid was extracted from the biological samples by modified Folch extraction method [26]. In brief, $0.05 \mathrm{~g}$ of solid samples (liver, heart tissues or FS) or $100 \mu \mathrm{l}$ of liquid samples (plasma or FSO) were homogenized in $5 \mathrm{ml}$ cold Folch solution (chloroform:methanol, 2:1, $\mathrm{v} / \mathrm{v})$ with $0.01 \%$ BHT $(\mathrm{w} / \mathrm{v})$ and $5 \mathrm{ng}$ of each internal standards at 24 , $000 \mathrm{rpm}$ in $20 \mathrm{~s}$ bursts on ice using a polytron benchtop homogenizer (T25, Ultra-Turrax, IKA, Germany). The homogenization was performed twice and the two parts of Folch solution extracts were combined. After $30 \mathrm{~min}$ incubation at room temperature on an orbital shaker, $2 \mathrm{ml}$ of $0.9 \%$ aqueous sodium chloride was added to allow phase separation. Afterwards, it was centrifuged at $4{ }^{\circ} \mathrm{C}, 3000 \times g$ for $10 \mathrm{~min}$ and the lower organic phase was collected in a glass vial. Then, $5 \mathrm{ml}$ of chloroform was added to the remaining upper phase holding tissue residues for re-extraction to increase the yield. The collected sample extracts were dried completely under a stream of nitrogen on $37^{\circ} \mathrm{C}$ heating block and then hydrolyzed by re-dissolving the samples in $1 \mathrm{ml}$ of $1 \mathrm{M}$ methanolic potassium hydroxide with $0.01 \%$ BHT and $1 \mathrm{ml}$ of PBS (pH 7.4). It was then placed on an orbital shaker and incubated in the dark overnight. The alkaline hydrolysis was terminated by adding $200 \mu \mathrm{l} 5 \mathrm{~N}$ hydrochloric acid, $0.5 \mathrm{ml}$ methanol, $2.7 \mathrm{ml} 40 \mathrm{mM}$ aqueous formic acid and 4 $\mathrm{ml} 20 \mathrm{mM}$ aqueous formic acid. The hydrolyzed samples were filtered with $0.45 \mu \mathrm{m}$ PTFE syringe to remove impurities. It was then extracted by solid phase extraction (SPE) using $60 \mathrm{mg}$ MAX columns (Oasis, Waters, USA) [27]. Accordingly, the samples were cleaned with hexane and $20 \mathrm{mM}$ formic acid, and the final analytes were eluted with $2 \mathrm{ml}$ of hexane and then $4 \mathrm{ml}$ of hexane/ethanol/acetic acid solution (70:29.4:0.6, v/v/v), and dried under a stream of nitrogen gas in the dark until complete dryness. The dried samples were resuspended in $100 \mu \mathrm{l}$ of acetonitrile. The prepared samples were aliquoted into autosampler vials with insert and immediately analyzed using LC-MS/MS.

\subsection{Quantification of PUFAs and oxidized PUFA products by LC-MS/MS}

PUFAs and oxidized PUFA products were analyzed according to previous studies with modifications [28-30]. Briefly, LC-MS/MS was performed by 1290 Infinity LC system (Agilent Technologies, USA) with a Kinetex C18 column $(150 \times 21 \mathrm{~mm}, 2.6 \mu \mathrm{m}$, Phenomenex, USA $)$. Milli-Q water: formic acid (99.9:0.1, v/v) and acetonitrile: formic acid (99.9:0.1, v/v) were used as solvent A and B respectively for the mobile phases in the LC system. The flow rate was $0.3 \mu \mathrm{l} / \mathrm{min}$ and a step-wise gradient elution was set as follows: first, $20 \% \mathrm{~B}$ was kept for the first
2 min, then a gradual elevation of B to $98 \%$ was achieved from 2 to 10 min and $98 \%$ B was maintained for 5 min. Finally, the mobile phase was set back to $20 \%$ B from 15 min to $15.1 \mathrm{~min}$ and kept until $20 \mathrm{~min}$ to prepare for the next run. The autosampler was operated at $4{ }^{\circ} \mathrm{C}$ and the injection volume of each sample was $10 \mu \mathrm{l}$.

For analytes detection, the LC system coupled to a QTrap 3200 triple quadrupole mass spectrometer (Sciex Applied Biosystem, MA, USA) with electrospray ionization (ESI) was used. The ESI was set to negative atmospheric pressure chemical ionization (APCI) mode and the analytes were detected by MS/MS using multiple reaction monitoring (MRM). The source temperature was set at $325^{\circ} \mathrm{C}$, the spray voltage was set to $-3000 \mathrm{~V}$, and nitrogen gas was used as curtain gas.

The quantification of each analyte was determined by correlating the peak area to its corresponding deuterated internal standard peak. For the analytes without its corresponding deuterated internal standards, quantitation was done by using deuterated internal standards with similar structures. In this study, a total of 6 PUFAs (arachidonic acid (AA), adrenic acid (AdA), ALA, docosapentaenoic acid (n-3 DPA), EPA and DHA) and 24 oxidized PUFA products were analyzed in the extracted samples. Detailed multiple reaction monitoring transition tables of measured PUFAs and oxidized PUFA products are shown in supplementary information, Table S2.

\subsection{RNA extraction and purification}

Total RNA was extracted from rat tissues using TRIzol reagent $(0.1 \mathrm{~g}$ tissue per $1 \mathrm{ml}$ TRIzol reagent) according to the manufacturer's protocol. The extracted RNA concentration and quality were determined with Nanodrop UV-Vis spectrophotometer (ND-2000; Thermo Fisher, USA) and the integrity of the extracted RNA were determined by $1 \%$ agarose gels electrophoresis. Prior to reverse transcription, purification of RNA samples was performed by using amplification grade deoxyribonuclease (DNase) I (Invitrogen, USA) according to the manufacturer's protocol. The purified samples were kept at $-20^{\circ} \mathrm{C}$ until further process.

\subsection{Reverse transcription and quantitative real-time polymerase chain reaction ( $q P C R)$}

The cDNA was generated from RNA using high capacity RNA-to cDNA kit (Applied Biosystems, USA) according to manufacturer's protocol. Real-time PCR reaction mixture was prepared by adding $1 \mu \mathrm{l}$ sample cDNA ( $\sim 40 \mathrm{ng} / \mu \mathrm{l}), 1 \mu \mathrm{l}$ forward and reverse primer mix $(10 \mu \mathrm{M}$, Invitrogen, USA), $3 \mu 1$ DEPC-water and $5 \mu 1$ XX SYBR green PCR master mix (Applied Biosystem, USA) into a 96 well plate. The reaction was run by Step-One Plus real-time thermal cycler (Applied Biosystem, CA, USA) and the PCR conditions were as followed: first, a hot start at $95{ }^{\circ} \mathrm{C}$ for 15 min, then denaturation with 40 cycles of $95{ }^{\circ} \mathrm{C}$ for $15 \mathrm{~s}$ and finally annealing at $60{ }^{\circ} \mathrm{C}$ for $1 \mathrm{~min}$. The primers used in this study (supplementary information, Table S3) were in-house designed and validated. The experiments were repeated thrice for data confirmation and reactions were measured in triplicates. The results obtained were calculated using ${ }^{\Delta \Delta} \mathrm{C}_{\mathrm{q}}$ method and recorded as fold changes.

\subsection{Statistical analysis}

All data were analyzed by GraphPad Prism (version 7 for PC, GraphPad Software, Inc., La Jolla, CA, USA) and reported as mean \pm SD. Data were analyzed by one-way analysis of variance (ANOVA), followed by Tukey's multiple comparison test. P-value of $<0.05$ was denoted as statistically significant. 


\section{Results}

3.1. Flaxseed had higher PhytoPs, PhytoFs and total phenolic content compared to flaxseed oil

ALA, PhytoPs and PhytoFs levels were measured in FS and FSO (Fig. 1) added to the diet. Concentrations of PhytoPs and PhytoFs in FS are significantly higher than FSO. Furthermore, the concentrations of total PhytoPs and PhytoFs in FS and FSO takes up $<0.01 \%$ and $<0.0001 \%$ per gram of ALA respectively. In addition, the total phenolic capacity of FSO was significantly lower compared to FS (Fig. 2). The difference indicates potential loss of the phenolic compounds and even PhytoPs and PhytoFs in the oil extraction process of FSO.

3.2. ALA enriched diets did not affect the weight gain and food intake of the rodents but reduced the heart to body weight ratio

ALA was supplemented in forms of FS and FSO in the diets. The bodyweight increased while bodyweight gained decreased throughout the feeding period for all supplemented groups. In addition, the amount of diet consumed by the rats was constant throughout the feeding period (Supplementary material, Fig. S1).

ISO treatment markedly elevated $(p<0.0001)$ the heart to body weight ratio of the rats compared to control. Furthermore, the ratio of FS + ISO and FSO + ISO were significantly higher than control but lower than ISO. Among the ISO treated groups, the ratio of FS + ISO group was the lowest compared to ISO (Table 1).

\subsection{Cardiac biomarkers in plasma were significantly reduced by $A L A-$} enriched diets

Rats injected with ISO alone showed significant elevated plasma LDH activity and cTnI level compared to control, indicating ISO administration successfully induced MI (Fig. 3). The activity of plasma LDH and cTnI levels were unaffected by the ALA-diets compared to the control. However, the elevated plasma LDH and cTnI by ISO was significantly reduced by the ALA-diets where the lowering effect was particularly strong by FS (approximately $40-50 \%$ for both) than FSO.

Graph showing (A) plasma lactate dehydrogenase (LDH) activity and (B) plasma concentration of cardiac troponin-1 (cTnI) measured in rat heart tissues. Plasma LDH activity is expressed as IU/L; 1 Unit (IU) of LDH will catalyze the conversion of $1 \mu$ mole of lactate to pyruvate per min. Data are presented in mean \pm S.D. $(n=4)$. ISO: isoproterenol was treated to the rats after supplementation period; FS: flaxseed; FSO: flaxseed oil. ${ }^{\# \# \#} \mathrm{p}<0.0001$ compared to control; **p $<0.01,{ }^{* * *} \mathrm{p}<$

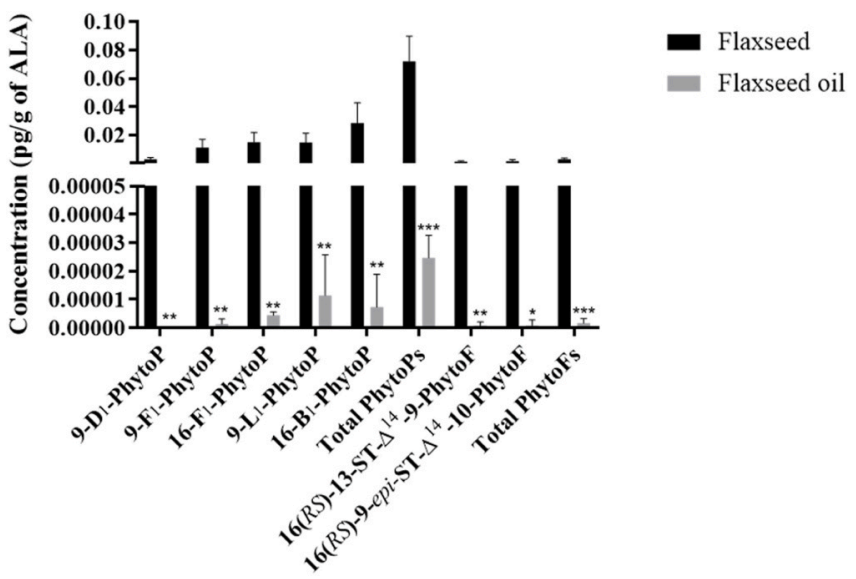

Fig. 1. Phytoprostane (PhytoP) and phytofurans (PhytoF) content per $1 \mathrm{~g}$ of ALA in flaxseed and flaxseed oil. Data are presented in mean \pm S.D. $(n=4)$. *p $<0.05,{ }^{* *} \mathrm{p}<0.01$ and ${ }^{* * *} \mathrm{p}<0.001$ compared to flaxseed.

\section{Total phenolic capacity}

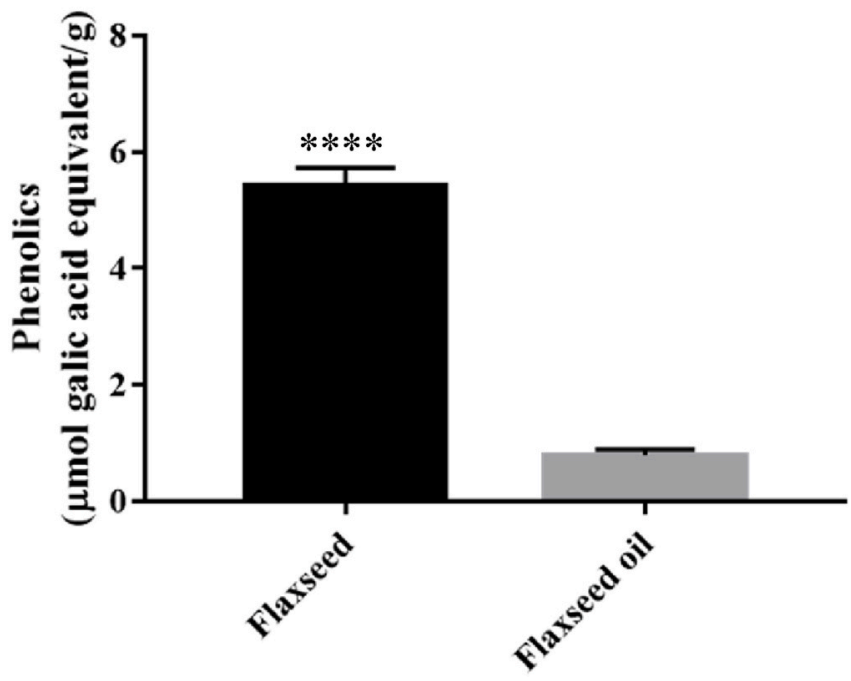

Fig. 2. Total phenolic capacity of flaxseed and flaxseed oil. Data are presented in mean \pm S.D. $(n=6)$. ${ }^{* * * *} \mathrm{p}<0.0001$ compared to flaxseed.

Table 1

Heart to body weight ratio in the treated rats supplemented with ALA-diet with or without ISO treatment.

\begin{tabular}{llll}
\hline Groups & Body weight $(\mathrm{g})$ & Heart weight $(\mathrm{g})$ & Heart to body weight ratio \\
\hline Control & $474.38 \pm 15.32$ & $1.497 \pm 0.015$ & $3.157 \pm 0.093$ \\
ISO & $502.33 \pm 24.75$ & $2.114 \pm 0.128$ & $4.206 \pm 0.056 * * * *$ \\
FS & $498.93 \pm 43.68$ & $1.584 \pm 0.080$ & $3.183 \pm 0.132$ \\
FS + ISO & $525.45 \pm 16.92$ & $1.923 \pm 0.057$ & $3.660 \pm 0.025 * * * * \# \# \#$ \\
FSO & $506.25 \pm 10.12$ & $1.640 \pm 0.041$ & $3.240 \pm 0.050$ \\
FSO + ISO & $495.25 \pm 19.53$ & $1.867 \pm 0.117$ & $3.768 \pm 0.125 * * * \# \#$
\end{tabular}

Data are presented in mean \pm S.D. $(n=4)$; ISO: isoproterenol; FS: flaxseed; FSO: flaxseed oil. $* * * p<0.001, * * * * p<0.0001$ compared to control.

$\# \#$ \# $<0.001$ and.

$\# \# \#$ $p<0.0001$ compared to ISO.

0.001 and $* * * * \mathrm{p}<0.0001$ compared to ISO.

3.4. ALA-diets elevated n-3 PUFA but not DHA, and reduced oxidative stress inflammatory mediators in the liver

Supplementation of FS and FSO increased the liver levels of n-3 PUFA, namely ALA, EPA and n-3 DPA. Moreover, DHA levels were unaltered while a reduction of $n-6$ PUFA including AA and AdA levels were observed (Fig. 4) in the ALA-diet groups. ISO reduced the PUFA levels and were lower than those given ALA-diet except for DHA.

ALA-diets reduced enzymatic oxidized products of AA, particularly 12-HETE and $\mathrm{PGF}_{2 \alpha}$ levels compared to control in the liver. However, ISO significantly augmented 5-, 8-, 12-, and 15-HETE levels while decreased the release of enzymatic oxidized products of DHA namely 4-, 7-, 11- and 14-HDHA levels in the control group. Both $\mathrm{PGF}_{2 \alpha}$ and 17HDHA levels were not affected by ISO (Table 2). Notably, in all ALAdiet groups treated with ISO showed reduced HETEs levels except for 12-HETE in FSO. Notwithstanding, levels of 11- and 14-HDHA in ALAdiet groups treated with ISO remained higher than control. Also, 7HDHA level was higher in FSO group compared to control after ISO treatment (Table 2).

As shown in Table 3, ALA-diet lowered non-enzymatic oxidation of $\mathrm{AA}$, in particular $5-\mathrm{F}_{2 \mathrm{t}}$-IsoP level by both diets but not $15-\mathrm{F}_{2 \mathrm{t}}$-IsoP level in the liver. As anticipated, ISO treatment induced $5-\mathrm{F}_{2 \mathrm{t}^{-}} \mathrm{IsoP}$ and $15-\mathrm{F}_{2 \mathrm{t}^{-}}$ IsoP levels in the control while those fed with ALA-diets resisted this elevation and remained low. 
A

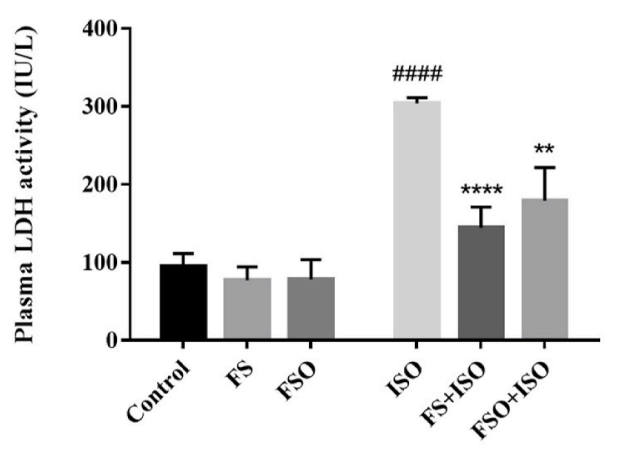

B

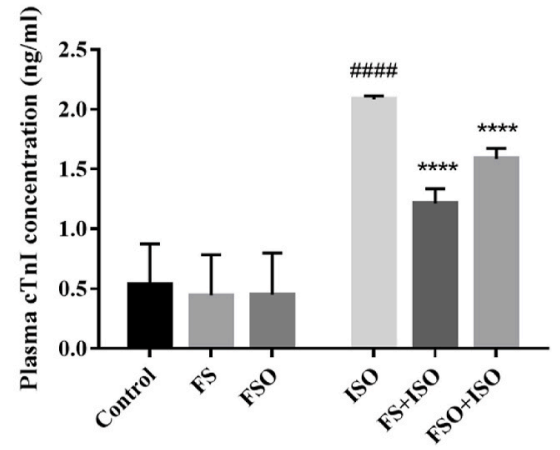

Fig. 3. Biochemical markers of cardiac injury measured in rat heart tissues.

A

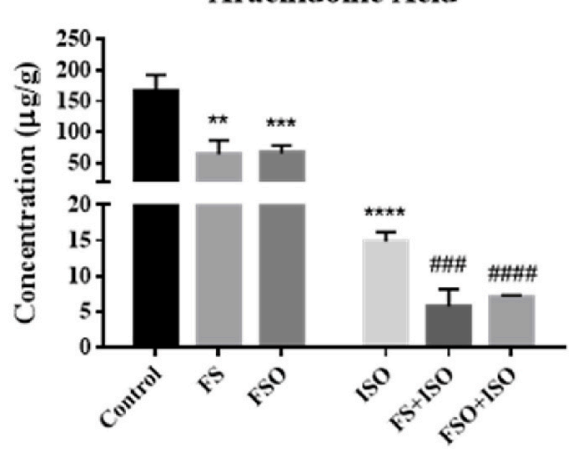

C

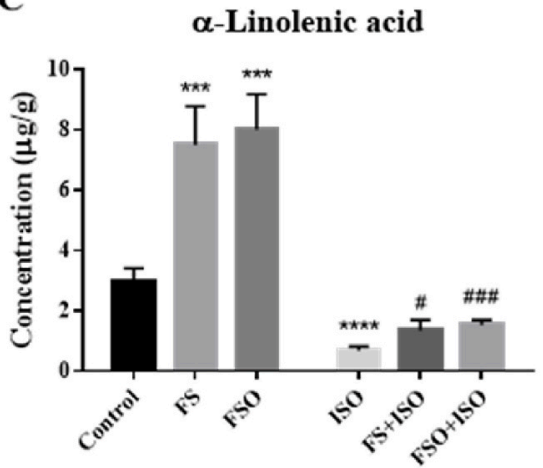

E n-3 Docosapentaenoic Acid

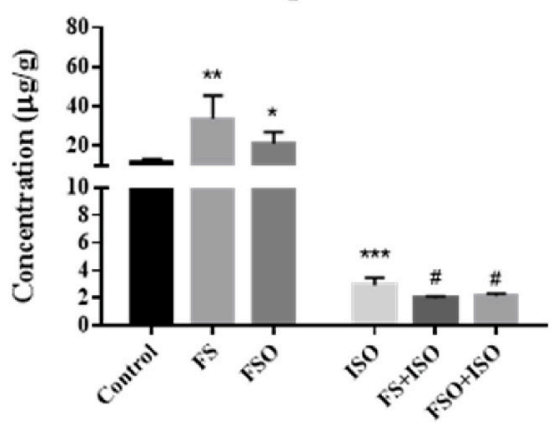

B

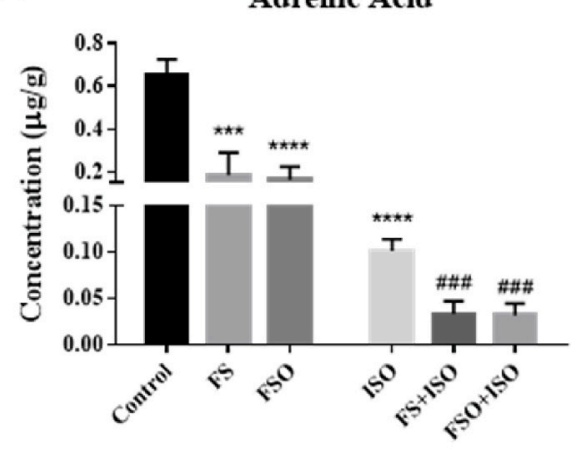

D

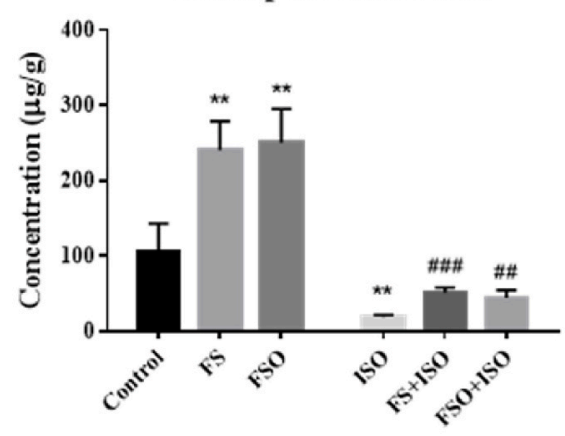

F

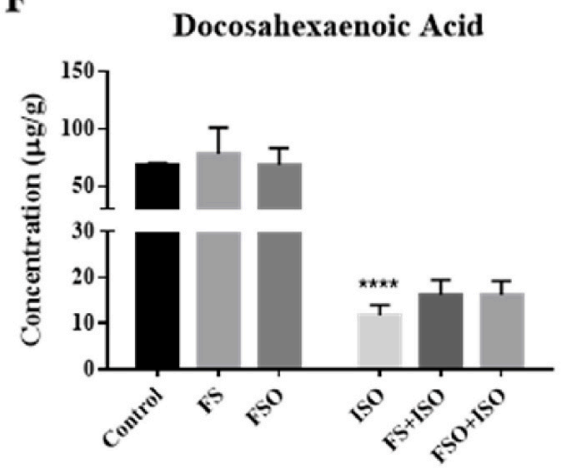

Fig. 4. Levels of PUFAs measured in rat liver tissues. 
Table 2

Levels of enzymatic oxidized PUFA products measured in rat liver tissues (ng/g tissue).

\begin{tabular}{|c|c|c|c|c|c|c|}
\hline & Control & FS & FSO & ISO & $\mathrm{FS}+\mathrm{ISO}$ & FSO + ISO \\
\hline \multicolumn{7}{|c|}{ Enzymatic oxidized lipid products from $A A$} \\
\hline 5-HETE & $0.12 \pm 0.08$ & $0.06 \pm 0.01$ & $0.17 \pm 0.04$ & $2.24 \pm 0.24 * * * *$ & $1.19 \pm 0.12^{\# \# \#}$ & $1.69 \pm 0.55$ \\
\hline 8-HETE & $0.93 \pm 0.23$ & $0.61 \pm 0.06^{*}$ & $0.76 \pm 0.19$ & $4.38 \pm 0.79^{* * *}$ & $2.23 \pm 0.48^{\# \#}$ & $1.74 \pm 0.43^{\# \#}$ \\
\hline 12-HETE & $2.21 \pm 0.21$ & $1.12 \pm 0.13^{* * *}$ & $1.49 \pm 0.32^{* *}$ & $4.96 \pm 0.58^{* * *}$ & $3.54 \pm 0.79^{\#}$ & $4.50 \pm 1.09$ \\
\hline 15-HETE & $0.09 \pm 0.02$ & $0.06 \pm 0.01$ & $0.08 \pm 0.02$ & $0.44 \pm 0.08^{* * *}$ & $0.22 \pm 0.05^{\#}$ & $0.17 \pm 0.04^{\#}$ \\
\hline PGF $_{2 \alpha}$ & $0.18 \pm 0.06$ & $0.06 \pm 0.03^{*}$ & $0.09 \pm 0.04^{*}$ & $0.18 \pm 0.04$ & $0.35 \pm 0.17$ & $0.16 \pm 0.03$ \\
\hline \multicolumn{7}{|c|}{ Enzymatic oxidized lipid products from DHA } \\
\hline 4-HDHA & $29.6 \pm 1.88$ & $3.23 \pm 0.33$ & $4.28 \pm 1.27$ & $0.36 \pm 0.14^{*}$ & $1.17 \pm 0.47^{\#}$ & $0.26 \pm 0.14$ \\
\hline 7-HDHA & $0.05 \pm 0.02$ & $0.09 \pm 0.02^{*}$ & $0.05 \pm 0.02$ & $0.15 \pm 0.04 * *$ & $0.15 \pm 0.06$ & $0.23 \pm 0.02^{\#}$ \\
\hline 11-HDHA & $17.78 \pm 8.21$ & $22.55 \pm 4.62$ & $6.78 \pm 3.68$ & $2.30 \pm 0.80^{* *}$ & $7.75 \pm 4.15^{\#}$ & $6.45 \pm 2.44^{\#}$ \\
\hline 14-HDHA & $6.90 \pm 2.19$ & $12.13 \pm 1.34^{* *}$ & $10.11 \pm 3.72$ & $0.34 \pm 0.11^{* * *}$ & $3.28 \pm 1.80^{\#}$ & $1.07 \pm 0.09^{\# \# \# \#}$ \\
\hline 17-HDHA & $44.08 \pm 23.30$ & $88.40 \pm 56.23$ & $37.51 \pm 4.98$ & $31.30 \pm 9.27$ & $55.81 \pm 14.74^{\#}$ & $74.17 \pm 34.29$ \\
\hline
\end{tabular}

Data are presented as mean \pm S.D. $(n=4)$. ISO: isoproterenol was treated to the rats after supplementation period; FS: flaxseed; FSO: flaxseed oil. HETE: hydroxyeicosatetraenoic acid; HDHA: hydroxy-docosahexaenoic acid. Concentration is shown as ng/g tissue samples. ${ }^{*} p<0.05,{ }^{* *} p<0.01,{ }^{* * *} p<0.001$ and ${ }^{* * * *} p<0.0001$

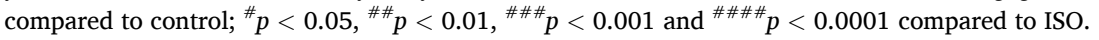

Table 3

Levels of non-enzymatic oxidized PUFA products measured in rat liver tissues (ng/g tissue).

\begin{tabular}{|c|c|c|c|c|c|c|}
\hline & Control & FS & FSO & ISO & $\mathrm{FS}+\mathrm{ISO}$ & FSO + ISO \\
\hline \multicolumn{7}{|c|}{ Non-enzymatic oxidized lipid products from $A A$} \\
\hline $5-F_{2 t}-$ IsoP & $3.93 \pm 1.80$ & $0.92 \pm 0.13^{*}$ & $0.45 \pm 0.35^{* *}$ & $22.31 \pm 5.84 * * *$ & $6.17 \pm 2.54^{\# \#}$ & $4.87 \pm 1.82^{\# \#}$ \\
\hline $15-\mathrm{F}_{2 \mathrm{t}}$-IsoP & $12.92 \pm 1.71$ & $11.67 \pm 1.38$ & $10.50 \pm 1.30$ & $33.16 \pm 7.51^{* *}$ & $19.80 \pm 3.44^{\#}$ & $15.73 \pm 2.55^{\# \#}$ \\
\hline \multicolumn{7}{|c|}{ Non-enzymatic oxidized lipid products from $A L A$} \\
\hline 9-D - -PhytoP & $13.05 \pm 6.80$ & $72.51 \pm 24.52^{* *}$ & $30.12 \pm 5.93^{* *}$ & $36.15 \pm 3.79 * *$ & $66.55 \pm 19.40^{\#}$ & $83.44 \pm 12.85^{\# \# \#}$ \\
\hline 9-F 1 -PhytoP & $8.27 \pm 3.15$ & $27.16 \pm 7.46^{* *}$ & $15.20 \pm 2.42^{*}$ & N.D. $* *$ & $12.10 \pm 5.08^{\# \#}$ & $19.30 \pm 2.19^{\# \# \# \#}$ \\
\hline 16-F $1 t^{-P h y t o P}$ & $3.88 \pm 1.91$ & $23.74 \pm 2.51^{* * * *}$ & $15.90 \pm 3.97^{* *}$ & $0.34 \pm 0.15^{*}$ & $6.79 \pm 4.23^{\#}$ & $4.41 \pm 2.08^{\# \#}$ \\
\hline 9-L $\mathrm{L}_{1}$-PhytoP & $4.63 \pm 2.80$ & $29.12 \pm 9.25^{* *}$ & $9.02 \pm 3.53^{* *}$ & $17.35 \pm 6.33^{*}$ & $60.96 \pm 6.68^{\# \# \# \#}$ & $41.04 \pm 14.69^{\#}$ \\
\hline 16-B 1 -PhytoP & $1.42 \pm 1.68$ & $40.73 \pm 10.96^{* * *}$ & $7.15 \pm 3.59^{*}$ & $1.24 \pm 0.65$ & $10.76 \pm 3.74^{\#}$ & $3.74 \pm 1.60^{\#}$ \\
\hline $16(R S)-13-S T-\Delta^{14}-9-P h y t o F$ & $0.71 \pm 0.16$ & $6.20 \pm 0.68^{* * * *}$ & $2.19 \pm 0.92^{*}$ & N.D. $* * *$ & $3.96 \pm 2.01^{\# \#}$ & $1.46 \pm 0.69^{\# \#}$ \\
\hline 16-(RS)-9-epi-ST- ${ }^{14}-10-P h y t o F$ & $0.85 \pm 0.55$ & $2.38 \pm 0.40 * * * *$ & $1.91 \pm 0.40 * *$ & N.D. ** & $2.24 \pm 0.87^{\# \#}$ & $1.17 \pm 0.14^{\# \# \#}$ \\
\hline \multicolumn{7}{|c|}{ Non-enzymatic oxidized lipid products from EPA } \\
\hline $5-F_{3 t^{-I s o P}}$ & $3.41 \pm 0.83$ & $5.54 \pm 0.78^{* *}$ & $2.32 \pm 0.53$ & $2.26 \pm 0.39 *$ & $3.15 \pm 1.77$ & $2.90 \pm 0.77$ \\
\hline 8-F $\mathrm{F}_{3 \mathrm{t}}$-IsoP & $1.79 \pm 1.46$ & $1.85 \pm 0.40$ & $1.61 \pm 1.37$ & $0.35 \pm 0.17^{*}$ & $5.00 \pm 1.99^{\# \#}$ & $4.65 \pm 0.84^{\# \# \# \#}$ \\
\hline \multicolumn{7}{|c|}{ Non-enzymatic oxidized lipid products from DHA } \\
\hline $4-\mathrm{F}_{4 \mathrm{t}}-\mathrm{NeuroP}$ & $5.54 \pm 1.03$ & $9.45 \pm 4.37$ & $7.57 \pm 1.52$ & $1.34 \pm 0.44^{* * *}$ & $8.16 \pm 3.66^{\# \# \#}$ & $7.55 \pm 1.53^{\#}$ \\
\hline $10-\mathrm{F}_{4 \mathrm{t}}-$ NeuroP & $8.88 \pm 1.12$ & $10.38 \pm 0.85$ & $8.93 \pm 2.64$ & $4.84 \pm 1.13^{* *}$ & $9.72 \pm 3.04^{\#}$ & $9.22 \pm 4.83$ \\
\hline 8-HDHA & $6.32 \pm 2.54$ & $6.70 \pm 3.14$ & $6.98 \pm 5.00$ & $4.29 \pm 1.64$ & $14.44 \pm 2.48^{\# \#}$ & $10.12 \pm 2.42^{\# \#}$ \\
\hline
\end{tabular}

Data are presented as mean \pm S.D. $(n=4)$. N.D.: not detected; ISO: isoproterenol was treated to the rats after supplementation period; FS: flaxseed; FSO: flaxseed oil. HDHA: hydroxy-docosahexaenoic acid; IsoP: isoprostane; PhytoP: phytoprostane; PhytoF: phytofuran; NeuroP: neuroprostane. ${ }^{*} p<0.05, * * p<0.01, * * * p<0.001$ and

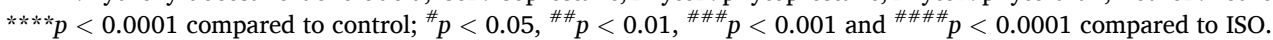

PhytoPs and PhytoFs, which are non-enzymatic oxidized products of ALA were enhanced by ALA-diets. When the rodents were treated with ISO, PhytoF (16 (RS)-13-ST- $\Delta^{14}-9$-PhytoF and 16-(RS)-9-epi-ST- $\Delta^{14}-10$ PhytoF) and 9- $\mathrm{F}_{1 \mathrm{t}}$-PhytoP levels were not found in the liver, whereas 9$\mathrm{D}_{1 \mathrm{t}}$-PhytoP, 9- $\mathrm{L}_{1}-\mathrm{PhytoP}$ and 16- $\mathrm{B}_{1}$-PhytoP levels were augmented but $16-\mathrm{F}_{1 \mathrm{t}}$-PhytoP level decreased, while 16- $\mathrm{B}_{1}$-PhytoP level was not altered compared to control without ISO treatment. However, ALA-diets resisted to the alteration by ISO, where PhytoP and PhytoF levels remained high and notably, PhytoF and 9- $\mathrm{F}_{1 \mathrm{t}}$-PhytoP levels were not inhibited (Table 3).

FS diet induced non-enzymatic oxidized product of EPA, namely 5$\mathrm{F}_{3 \mathrm{t}}$-IsoP level compared to the control but not in FSO group. Furthermore, levels of $8-\mathrm{F}_{3 \mathrm{t}^{-}}$-IsoP were not modified by the ALA-diets. Both $5-\mathrm{F}_{3 \mathrm{t}^{-}}$ IsoP and $8-\mathrm{F}_{3 \mathrm{t}}$-IsoP levels were reduced by ISO treatment to control, moreover, 8- $\mathrm{F}_{3 \mathrm{t}}$-IsoP level remained higher than control in all ALA-diet groups while $5-\mathrm{F}_{3 \mathrm{t}}$-IsoP level was not modified (Table 3).

Of the non-enzymatic oxidized products of DHA, treatment of ISO decreased $4-\mathrm{F}_{4 \mathrm{t}}-\mathrm{NeuroP}$ and $10-\mathrm{F}_{4 \mathrm{t}}-\mathrm{NeuroP}$ levels compared to control, while no change was found for 8-HDHA. ALA-diets resisted to the oxidative stress by ISO treatment where 4- $\mathrm{F}_{4 \mathrm{t}}-$ NeuroP, $10-\mathrm{F}_{4 \mathrm{t}}$-NeuroP, 8HDHA levels were higher than control (Table 3).

ISO: isoproterenol was treated to the rats after supplementation period; FS: flaxseed; FSO: flaxseed oil. ${ }^{*} p<0.05,{ }^{* *} p<0.01,{ }^{* * *} p<$ 0.001 and ${ }^{* * * *} p<0.0001$ compared to control; ${ }^{\#} p<0.05,{ }^{\# \#} p<0.01$ and ${ }^{\# \# \#} p<0.001$ compared to ISO.

3.5. ALA-diets elevated n-3 PUFA but not DHA in the heart tissues, and modulated oxidative stress and inflammatory mediators against MI injury

Supplementation of FS and FSO increased ALA, EPA and n-3 DPA levels but reduced AA and AdA levels compared to control in the heart tissues (Fig. 5). DHA levels were unaltered by the ALA-diets. ISO treatment reduced the PUFA levels compared to control without ISO. However, ISO treatment further reduced AA and AdA levels but not for ALA and EPA levels. Levels of n-3 DPA and DHA were unaffected by ISO treatment in the ALA-diet groups.

ALA-diet showed little effect on the levels of enzymatic oxidized products of PUFA in the heart tissues (Table 4). Levels of 15-HETE were reduced by all ALA-diets, where FS diet induced 4- and 7-HDHA, and FSO induced 7-HDHA levels when compared to control. ISO treatment enhanced all enzymatic oxidized products of AA except for $\mathrm{PGF}_{2 \alpha}$, while it did not modify products of DHA compared to control. Moreover, ALAdiets reduced 12-HETE levels while no changes were observed for 5-, 8and 15-HETE and $\mathrm{PGF}_{2 \alpha}$ levels. Although ISO treatment to control group had no effect on HDHAs, ALA-diets elevated all HDHA levels.

As oppose to the liver, all ALA-diets reduced 15- $\mathrm{F}_{2 \mathrm{t}}$-IsoP levels and 5$\mathrm{F}_{2 \mathrm{t}}$-IsoP level by FS diet only compared to control in the heart tissues. Elevated levels of all PhytoPs $\left(9-\mathrm{D}_{1 \mathrm{t}^{-}}, 9-\mathrm{F}_{1 \mathrm{t}^{-}}, 16-\mathrm{F}_{1 \mathrm{t}^{-}}, 9-\mathrm{L}_{1^{-}}\right.$and $16-\mathrm{B}_{1^{-}}$ 
A

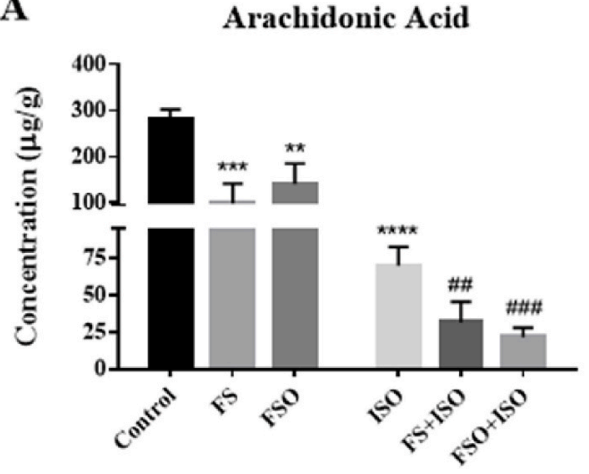

C

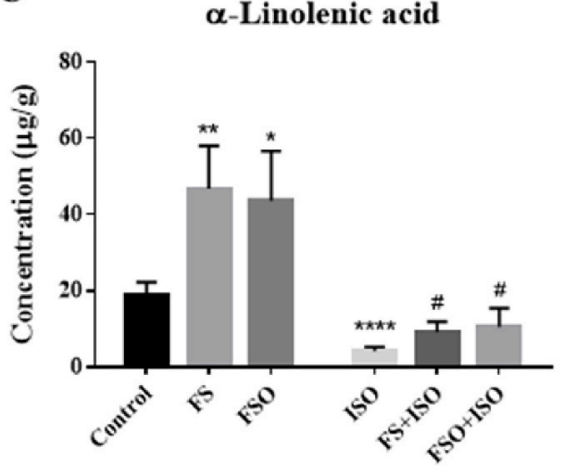

$\mathbf{E}$

n-3 Docosapentaenoic Acid

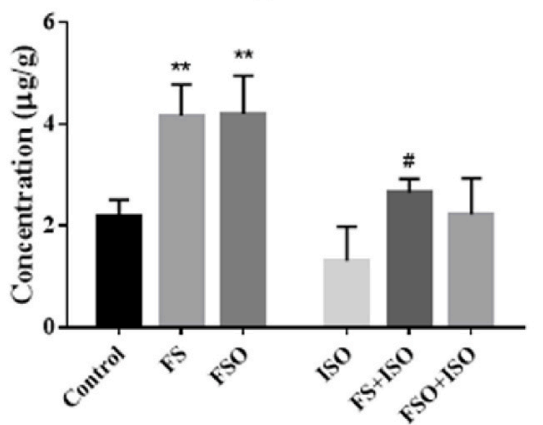

B

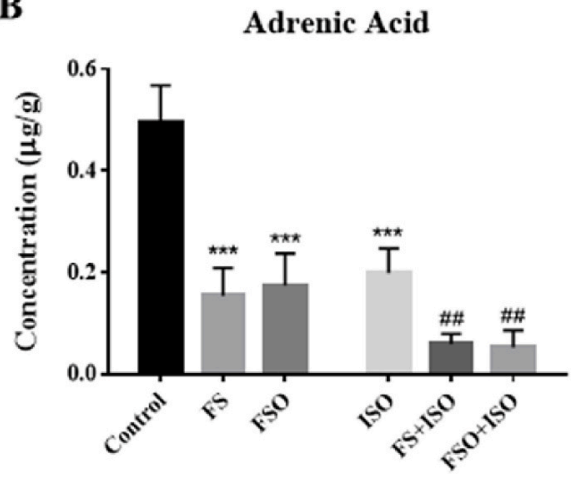

D

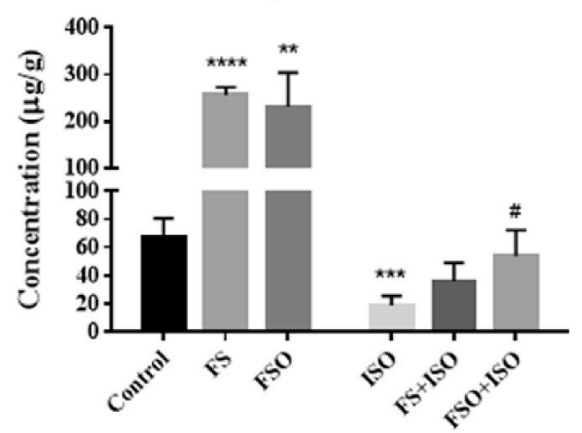

F
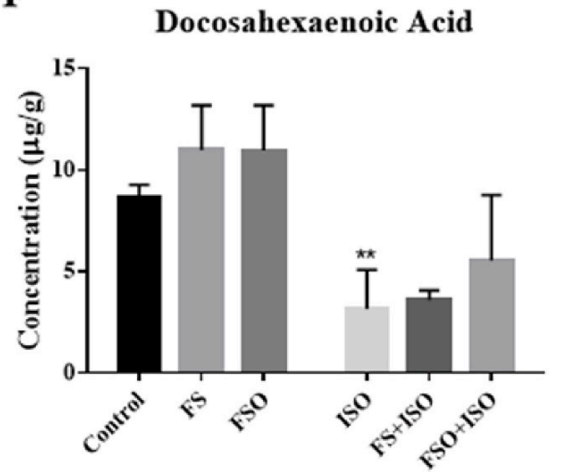

Fig. 5. Levels of PUFAs measured in rat heart tissues.

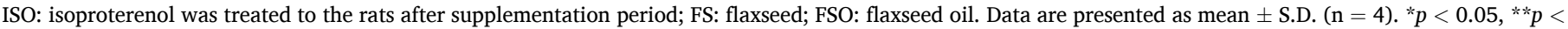
$0.01,{ }^{* *} p<0.001$ and ${ }^{* * * *} p<0.0001$ compared to control; ${ }^{*} p<0.05$ and ${ }^{\# \#} p<0.01$ compared to ISO.

Table 4

Levels of enzymatic oxidized lipid products measured in rat heart tissues (ng/g tissue).

\begin{tabular}{|c|c|c|c|c|c|c|}
\hline & Control & FS & FSO & ISO & $\mathrm{FS}+\mathrm{ISO}$ & FSO + ISO \\
\hline \multicolumn{7}{|c|}{ Enzymatic oxidized lipid products from $A A$} \\
\hline 5-HETE & $0.48 \pm 0.13$ & $0.62 \pm 0.05$ & $0.34 \pm 0.08$ & $1.19 \pm 0.16^{* * *}$ & $1.01 \pm 0.21$ & $1.40 \pm 0.26$ \\
\hline 8-HETE & $1.07 \pm 0.30$ & $0.82 \pm 0.10$ & $0.98 \pm 0.29$ & $2.11 \pm 0.19^{* *}$ & $1.60 \pm 0.45$ & $1.83 \pm 0.45$ \\
\hline 12-HETE & $4.83 \pm 1.32$ & $4.76 \pm 0.85$ & $6.31 \pm 3.19$ & $13.13 \pm 0.93^{* * * *}$ & $7.47 \pm 2.26^{\# \#}$ & $8.31 \pm 2.07^{\# \#}$ \\
\hline 15-HETE & $0.52 \pm 0.08$ & $0.29 \pm 0.06^{* *}$ & $0.21 \pm 0.09 * *$ & $0.77 \pm 0.13^{*}$ & $0.57 \pm 0.12$ & $0.99 \pm 0.31$ \\
\hline PGF $_{2 \alpha}$ & $0.10 \pm 0.05$ & $0.07 \pm 0.02$ & $0.10 \pm 0.01$ & $0.15 \pm 0.03$ & $0.12 \pm 0.02$ & $0.19 \pm 0.07$ \\
\hline \multicolumn{7}{|c|}{ Enzymatic oxidized lipid products from DHA } \\
\hline 4-HDHA & $0.07 \pm 0.06$ & $0.34 \pm 0.16^{*}$ & $0.14 \pm 0.03$ & $0.13 \pm 0.06$ & $0.45 \pm 0.11^{\# \#}$ & $0.57 \pm 0.23^{\# \#}$ \\
\hline 7-HDHA & $0.35 \pm 0.15$ & $0.67 \pm 0.08^{* *}$ & $0.73 \pm 0.10^{* *}$ & $0.22 \pm 0.08$ & $1.49 \pm 0.36^{\# \# \#}$ & $1.10 \pm 0.28^{\# \# \#}$ \\
\hline 11-HDHA & $1.25 \pm 0.91$ & $1.99 \pm 1.05$ & $1.64 \pm 0.33$ & $2.70 \pm 1.80$ & $6.49 \pm 2.42^{\#}$ & $6.72 \pm 1.83^{\#}$ \\
\hline 14-HDHA & $0.44 \pm 0.07$ & $0.44 \pm 0.18$ & $0.47 \pm 0.23$ & $1.17 \pm 0.67$ & $3.61 \pm 1.09^{\# \#}$ & $4.72 \pm 1.10^{\# \#}$ \\
\hline 17-HDHA & $6.23 \pm 0.64$ & $4.10 \pm 2.35$ & $7.81 \pm 4.04$ & $11.46 \pm 7.31$ & $84.24 \pm 23.77^{\# \#}$ & $57.92 \pm 23.51^{\# \#}$ \\
\hline
\end{tabular}

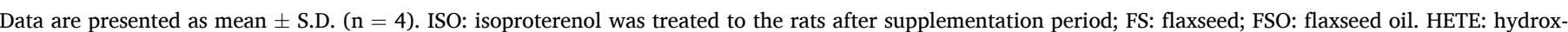

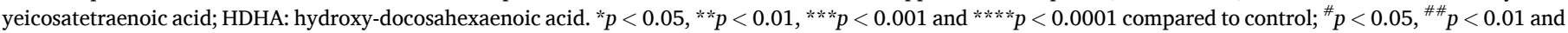
$\# \# \#<0.001$ compared to ISO. 
PhytoP) and PhytoFs (16 (RS)-13-ST- $\Delta^{14}$-9-PhytoF and 16-(RS)-9-epiST- $\Delta^{14}$-10-PhytoF) were observed by all ALA-diets compared to control. Nonetheless, treatment of ISO only elevated $9-\mathrm{D}_{1 \mathrm{t}^{-}}$and $16-\mathrm{F}_{1 \mathrm{t}}$-PhytoP and reduced 9- $\mathrm{F}_{1 \mathrm{t}}$-PhytoP levels compared to control. Regardless, compared to control, all ALA-diets augmented the levels of all PhytoPs and PhytoFs when treated with ISO (Table 5).

ALA-diets did not affect non-enzymatic oxidized products of EPA when compared to control in the heart tissues. When treated with ISO, only $5-\mathrm{F}_{3 \mathrm{t}}$-IsoP level elevated compared to control. Among the ALAdiets, only FS diet retained high $5-\mathrm{F}_{3} \mathrm{t}-\mathrm{IsoP}$ level compared to control when treated with ISO (Table 5).

As like the liver, treatment of ISO reduced $4-\mathrm{F}_{4 \mathrm{t}^{-}} \mathrm{NeuroP}, 10-\mathrm{F}_{4 \mathrm{t}^{-}}$ NeuroP and 8-HDHA compared to control. Surprisingly, all ALA-diet groups showed induced $4-\mathrm{F}_{4 \mathrm{t}}$-NeuroP and 8-HDHA levels when treated with ISO compared to control. No alteration was observed for $10-\mathrm{F}_{4 \mathrm{t}^{-}}$ NeuroP in ALA-diet groups when treated with ISO (Table 5).

\subsection{ALA-diets elevated n-3 PUFA but not DHA, and reduced inflammatory lipid mediators in the plasma}

Supplementation of FS and FSO increased plasma ALA and EPA levels but reduced AA and AdA levels compared to control. No changes were observed in the levels of n-3 DPA and DHA (Fig. 6). ISO treatment did not alter the levels of all PUFAs compared to control. Supplementation of FS and FSO also increased the levels of ALA and EPA levels but reduced AA and AdA levels when compared to ISO group.

ALA diets did not show significant alterations in the levels of enzymatic oxidized products of PUFA in the plasma compared to control (Table 6). ISO treatment led to an elevation of LOX-mediated HETEs including 5-, 8-, 12- and 15-HETE compared to control. However, both FS and FSO supplementation reduced all LOX-mediated HETEs levels compared to ISO group. For enzymatic oxidized DHA products, ISO treatment only reduced 11-HDHA significantly compared to control. FS diet elevated 4-, 11- and 17-HDHA when compared to ISO group while FSO diet elevated 17-HDHA only.

As like our observation in the heart tissues, ISO treatment caused a significant elevation in both $5-\mathrm{F}_{2 \mathrm{t}}$-IsoP and $15-\mathrm{F}_{2 \mathrm{t}}$-IsoP compared to control in plasma. Furthermore, supplementation of FS and FSO reduced $5-\mathrm{F}_{2 \mathrm{t}}$-IsoP and $15-\mathrm{F}_{2 \mathrm{t}}$-IsoP in ISO groups (Table 7). Elevated levels of all PhytoPs (9-D ${ }_{1 t^{-}}, 9-\mathrm{F}_{1 t^{-}}, 16-\mathrm{F}_{1 t^{-}}, 9-\mathrm{L}_{1^{-}}$and 16-B $1_{1}$-PhytoP) and PhytoFs (16 (RS)-13-ST- $\Delta^{14}$-9-PhytoF and 16-(RS)-9-epi-ST- $\Delta^{14}-10-$ PhytoF) were observed by ALA diets compared to control in both with and without ISO treatment.
ISO treatment did not alter the levels of plasma non-enzymatic oxidized products of EPA compared to control. Moreover both FS and FSO diets did not alter these levels compared to control and ISO groups. However, ALA diets showed an effect on the levels of non-enzymatic oxidized products of DHA in the plasma (Table 7). FS and FSO elevated the levels of $4-\mathrm{F}_{4 \mathrm{t}}-\mathrm{NeuroP}$ and $10-\mathrm{F}_{4 \mathrm{t}}$-NeuroP in both control with and without ISO treatment. In addition, FS diet elevated 8-HDHA significantly compared to control.

\subsection{ALA-diets up-regulated catalase and down-regulated IL1 $\beta, I L 6$ and TNF $\alpha$ gene expressions in the heart tissues injured by $M I$}

As shown in Fig. 7, ALA-diets reduced TNF $\alpha$ gene expressions only while expression of catalase was augmented compared to control in heart tissues.

ISO treatment elevated the gene expressions of inflammatory markers including IL1 $\beta$, IL6 and TNF $\alpha$. The inflammatory response by ISO treatment appeared to be resolved by all ALA-diets where a marked reduction in IL1 $\beta$, IL6 and TNF $\alpha$ expressions were observed. ISO treatment also reduced the antioxidant capacity of cardiomyocytes through catalase. However, a resistance was observed in ALA-diet groups where it was up-regulated compared to control (Fig. 7).

\section{Discussion}

In this study, ISO was used to induce MI in the rats. It is a potent synthetic catecholamines which regulates cardiac muscle contractility and metabolism. However, excessive amount of ISO causes increased heart rate, subendocardial myocardial ischemia, hypoxia, cardiomyocyte necrosis and develop infarct-like lesions in the rat heart tissues which are similar to pathophysiology of human MI. The physiological changes triggered by ISO in the rat heart is due to excessive production of free radicals from oxidative metabolism by catecholamines [19].

Heart weight to body weight ratio is one of the simplest ways to assess cardiac injury where an increase also indicates cardiac hypertrophy. Development of hypertrophy can be caused by water accumulation in edematous intramuscular spaces of cardiac muscle, increased protein content in cardiac muscle due to increased gene expression of proteins related to contractile unit and the activation of hypertrophic response in cardiac cells due to the influx of cytoplasmic calcium during MI [31]. In Derbali et al. study, it was found ISO-induced MI that led to $57 \%$ elevation of the ratio in rats whereas pretreatment with FSO

Table 5

Levels of non-enzymatic oxidized lipid products measured in rat heart tissues (ng/g tissue).

\begin{tabular}{|c|c|c|c|c|c|c|}
\hline & Control & FS & FSO & ISO & $\mathrm{FS}+\mathrm{ISO}$ & $\mathrm{FSO}+\mathrm{ISO}$ \\
\hline \multicolumn{7}{|c|}{ Non-enzymatic oxidized lipid products from $A A$} \\
\hline $5-F_{2 t}$-IsoP & $12.77 \pm 0.98$ & $5.07 \pm 3.08 * *$ & $16.62 \pm 6.65$ & $44.25 \pm 5.62^{* * * *}$ & $32.46 \pm 4.23^{\#}$ & $20.64 \pm 5.85^{\# \#}$ \\
\hline $15-F_{2 t}$-IsoP & $140.07 \pm 26.67$ & $46.07 \pm 17.94 * *$ & $65.25 \pm 15.07^{* *}$ & $179.47 \pm 17.17^{*}$ & $96.82 \pm 36.84^{\# \#}$ & $125.55 \pm 37.08^{\#}$ \\
\hline \multicolumn{7}{|c|}{ Non-enzymatic oxidized lipid products from ALA } \\
\hline 9-D $1 t^{-P h y t o P}$ & $0.51 \pm 0.21$ & $3.63 \pm 1.32^{*}$ & $3.50 \pm 1.30^{*}$ & $3.25 \pm 1.10^{*}$ & $7.89 \pm 1.03^{\# \# \#}$ & $6.20 \pm 0.83^{\# \#}$ \\
\hline 9-F $1 \mathrm{t}^{-\mathrm{PhytoP}}$ & $1.10 \pm 0.53$ & $1.15 \pm 0.52^{*}$ & $1.81 \pm 0.45^{* * *}$ & $0.86 \pm 0.29 *$ & $2.20 \pm 0.48^{\# \#}$ & $2.62 \pm 0.40^{\# \# \#}$ \\
\hline 16-F $1 t^{-P h y t o P}$ & $1.59 \pm 0.73$ & $16.34 \pm 1.19^{* * * *}$ & $15.45 \pm 3.17 * * * *$ & $4.53 \pm 1.51^{* *}$ & $16.26 \pm 4.51^{\# \#}$ & $9.67 \pm 2.83$ \\
\hline 9-L $\mathrm{L}_{1}$-PhytoP & $0.81 \pm 0.41$ & $2.63 \pm 0.16^{* * * *}$ & $1.78 \pm 0.52^{* *}$ & $1.07 \pm 0.40$ & $3.73 \pm 0.60^{\# \# \#}$ & $3.45 \pm 0.64^{\# \# \#}$ \\
\hline 16-B 1 -PhytoP & $0.32 \pm 0.09$ & $18.32 \pm 3.72^{* * * *}$ & $10.43 \pm 2.95^{* * *}$ & $2.05 \pm 0.89$ & $14.73 \pm 3.23^{\# \# \#}$ & $16.39 \pm 2.37^{\# \# \# \#}$ \\
\hline $16(R S)-13-S T-\Delta^{14}-9-P h y t o F$ & $0.72 \pm 0.39$ & $3.75 \pm 0.73^{* * *}$ & $4.46 \pm 0.69^{* * * *}$ & $0.75 \pm 0.21$ & $6.83 \pm 1.43^{\# \# \#}$ & $3.93 \pm 0.89^{\# \# \#}$ \\
\hline 16-(RS)-9-epi-ST- ${ }^{14}-10-P h y t o F$ & $0.49 \pm 0.13$ & $2.81 \pm 0.69 * * *$ & $2.78 \pm 0.33^{* * * *}$ & $0.92 \pm 0.26$ & $5.89 \pm 0.77^{\# \# \# \#}$ & $4.58 \pm 0.68^{\# \# \# \#}$ \\
\hline \multicolumn{7}{|c|}{ Non-enzymatic oxidized lipid products from EPA } \\
\hline 5-F Ft-IsoP $^{-}$ & $5.86 \pm 1.92$ & $3.85 \pm 1.14$ & $13.16 \pm 8.14$ & $28.40 \pm 6.29^{* * *}$ & $52.95 \pm 8.27^{\# \#}$ & $34.28 \pm 17.00$ \\
\hline 8-F Ft $^{-I s o P}$ & $0.65 \pm 0.36$ & $0.60 \pm 0.24$ & $0.52 \pm 0.26$ & $0.78 \pm 0.23$ & $0.92 \pm 0.17$ & $1.17 \pm 0.35$ \\
\hline \multicolumn{7}{|c|}{ Non-enzymatic oxidized lipid products from DHA } \\
\hline 4-F $4 \mathrm{t}-$ NeuroP & $10.50 \pm 2.58$ & $11.39 \pm 3.19$ & $11.68 \pm 2.24$ & $6.62 \pm 1.64^{*}$ & $15.36 \pm 2.63^{\# \#}$ & $14.64 \pm 3.03^{\# \#}$ \\
\hline $10-\mathrm{F}_{4 \mathrm{t}}-$ NeuroP & $14.44 \pm 5.10$ & $16.81 \pm 2.83$ & $16.89 \pm 2.65$ & $2.94 \pm 1.64 * *$ & $7.32 \pm 3.57$ & $6.58 \pm 2.82$ \\
\hline 8-HDHA & $0.94 \pm 0.13$ & $1.02 \pm 0.42$ & $1.19 \pm 0.34$ & $0.54 \pm 0.21^{*}$ & $1.58 \pm 0.38^{\# \#}$ & $1.13 \pm 0.27^{\#}$ \\
\hline
\end{tabular}

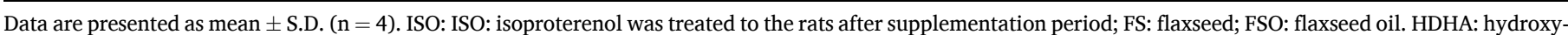

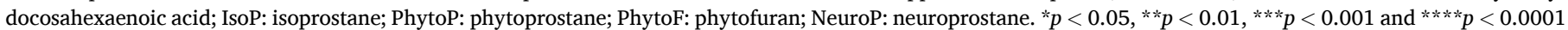
compared to control; ${ }^{\#} p<0.05,{ }^{\# \#} p<0.01$, ${ }^{\# \#} p<0.001$ and ${ }^{\# \# \# \# ~} p 0.0001$ compared to ISO. 
Arachidonic Acid

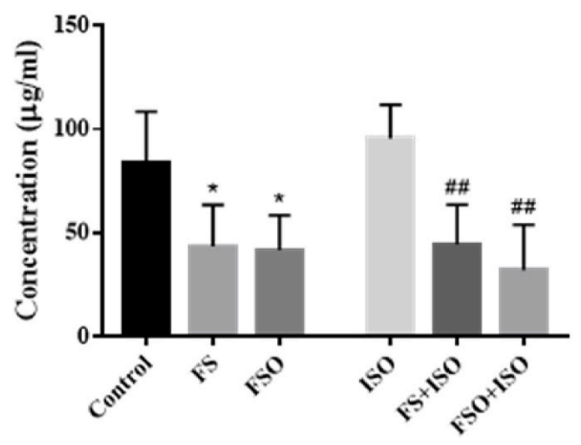

$\alpha$-Linolenic acid

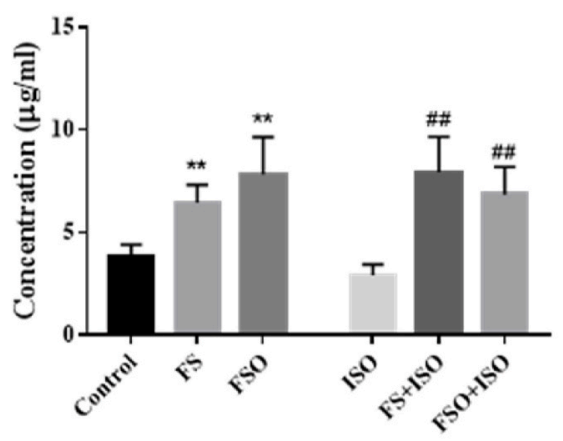

n-3 Docosapentaenoic Acid

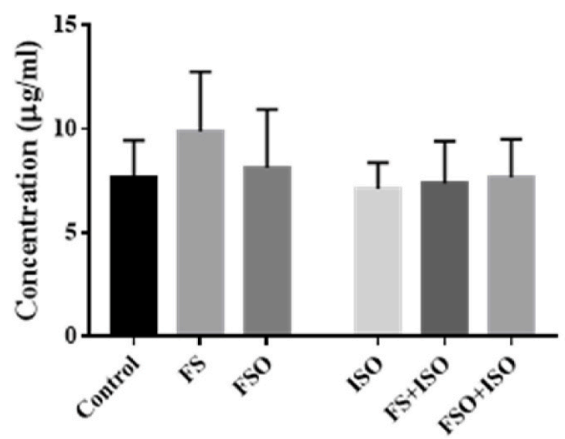

Adrenic Acid

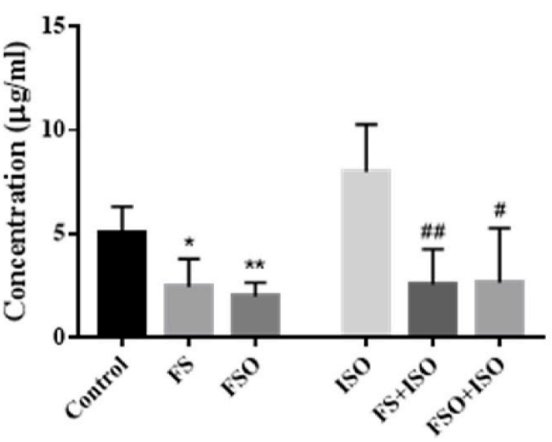

Eicosapentaenoic Acid

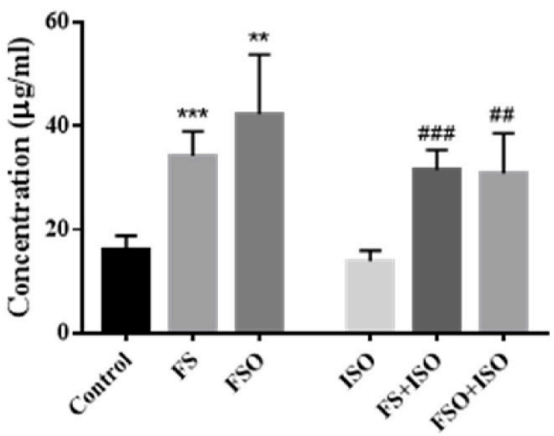

Docosahexaenoic Acid

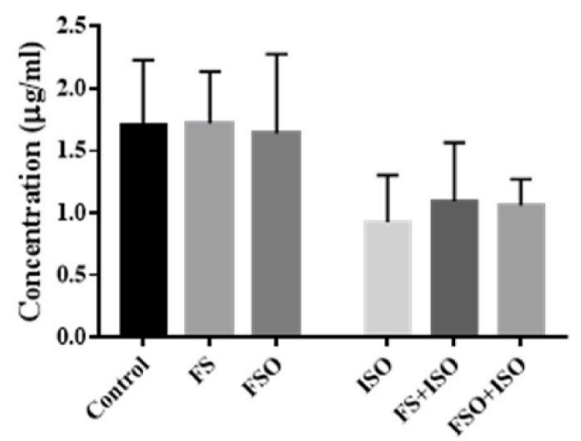

Fig. 6. Levels of PUFAs measured in rat plasma.

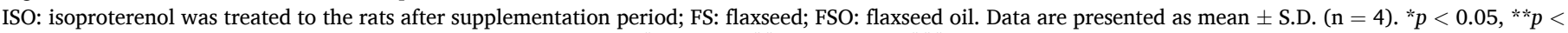
0.01 and ${ }^{* * *} p<0.001$ and ${ }^{* * * *} p<0.0001$ compared to control; ${ }^{*} p<0.05$, ${ }^{\# \#} p<0.01$ and ${ }^{\# \# \#} p<0.001$ compared to ISO.

reduced the ratio by $27 \%$ [32]. Similarly, we showed that the ratio increased significantly in ISO-induced MI rats by $33 \%$ compared to healthy control rats, indicating that cardiac hypertrophy took place. Indeed, marked reduction of the ratio with ALA-diets especially FS, suggest the diet to be anti-hypertrophic and able to protect the heart against stress.

The cardioprotective effect of ALA-diets were further demonstrated by plasma cTnI level and LDH activity. Plasma cTn (I or T) is the most preferred biomarker for cardiac necrosis due to its high sensitivity and specificity [33] while LDH is the first diagnostic enzyme for myocardial infarction [34]. It was found that LDH are released to the extracellular fluid in myocardial injury. Several animal studies reported that Pretreatment with ALA-diet including pure ALA [35], flaxseed oil [32] and chia seed [36] can prevent the elevation of plasma cTnI and LDH in MI rats. Results in this study showed massive increase in cTnI and LDH activities in rat plasma after ISO-induced MI. Likewise, FS diet had the strongest lowering effect of these two cardiac injury markers, indicating potential cardio-protective effect.

All ALA-diets modified the lipid profiles in the liver and heart tissues, and plasma. A significant reduction of n-6 PUFA namely AA and AdA, and elevation of n-3 PUFA, namely ALA and EPA were found in all tissues and plasma of rats fed with ALA-diets. It matched the results in Poudyal et al. study, where chia seed supplementation increased cardiac and liver n-3: n-6 PUFA ratio and suggested to be attributed by high dietary intake of ALA in chia seeds [36]. The elevation of ALA in the tissues suggest competition with LA for the elongase and desaturase enzymes for the in vivo synthesis of longer chain and more unsaturated PUFA in the liver. Our observation suggests ALA enriched diet increased the conversion of ALA to EPA and DPA and decreased the conversion of LA to AA and AdA. The unchanged level of DHA confirms the poor conversion efficacy of ALA to DHA in vivo where typically, only $1 \%-5 \%$ of ALA is converted to DHA [37]. Sprecher et al. suggested that the low conversion efficiency of DHA from ALA is due to the need of $\Delta^{6}$ desaturase enzyme twice in the metabolic pathway. An increased amount of 
Table 6

Levels of enzymatic oxidized PUFA products measured in rat plasma $(\mathrm{ng} / \mathrm{ml})$.

\begin{tabular}{|c|c|c|c|c|c|c|}
\hline & Control & FS & FSO & ISO & $\mathrm{FS}+\mathrm{ISO}$ & $\mathrm{FSO}+\mathrm{ISO}$ \\
\hline \multicolumn{7}{|c|}{ Enzymatic oxidized lipid products from $A A$} \\
\hline 5-HETE & $5.29 \pm 1.33$ & $4.21 \pm 1.81$ & $5.18 \pm 2.36$ & $14.30 \pm 6.73^{*}$ & $4.95 \pm 0.47^{\#}$ & $4.15 \pm 0.61^{\#}$ \\
\hline 8-HETE & $1.14 \pm 0.31$ & $0.89 \pm 0.50$ & $1.89 \pm 1.17$ & $5.70 \pm 2.88^{*}$ & $1.84 \pm 0.67^{\#}$ & $1.64 \pm 0.36^{\#}$ \\
\hline 12-HETE & $5.61 \pm 0.60$ & $8.08 \pm 2.40$ & $6.43 \pm 1.68$ & $14.10 \pm 5.91 *$ & $2.50 \pm 1.54^{\# \#}$ & $2.10 \pm 0.55^{\# \#}$ \\
\hline 15-HETE & $0.82 \pm 0.40$ & $0.61 \pm 0.24$ & $0.66 \pm 0.16$ & $2.13 \pm 0.88^{*}$ & $0.53 \pm 0.33^{\#}$ & $0.46 \pm 0.13^{\#}$ \\
\hline $\mathrm{PGF}_{2 \alpha}$ & $3.01 \pm 1.43$ & $2.24 \pm 0.09$ & $1.98 \pm 1.37$ & $1.60 \pm 0.78$ & $2.03 \pm 1.16$ & $1.86 \pm 1.67$ \\
\hline \multicolumn{7}{|c|}{ Enzymatic oxidized lipid products from $D H A$} \\
\hline 4-HDHA & $11.41 \pm 4.70$ & $18.56 \pm 9.55$ & $15.20 \pm 3.65$ & $14.01 \pm 4.03$ & $24.91 \pm 4.74^{\#}$ & $23.96 \pm 9.02$ \\
\hline 7-HDHA & $5.56 \pm 3.14$ & $7.02 \pm 2.81$ & $6.17 \pm 1.87$ & $5.59 \pm 1.86$ & $3.51 \pm 0.33$ & $2.99 \pm 1.06$ \\
\hline 11-HDHA & $17.62 \pm 5.16$ & $24.26 \pm 10.88$ & $18.92 \pm 6.44$ & $10.60 \pm 2.40^{*}$ & $17.29 \pm 4.48^{\#}$ & $16.54 \pm 7.45$ \\
\hline 14-HDHA & $2.60 \pm 1.11$ & $4.04 \pm 2.45$ & $5.39 \pm 4.66$ & $2.01 \pm 0.68$ & $3.03 \pm 0.63$ & $2.40 \pm 0.84$ \\
\hline 17-HDHA & $3.76 \pm 1.25$ & $5.60 \pm 2.43$ & $4.37 \pm 2.66$ & $2.72 \pm 1.54$ & $8.64 \pm 3.00^{\#}$ & $8.20 \pm 2.00^{\# \#}$ \\
\hline
\end{tabular}

Data are presented as mean \pm S.D. $(n=4)$. ISO: isoproterenol was treated to the rats after supplementation period; FS: flaxseed; FSO: flaxseed oil. HETE: hydroxyeicosatetraenoic acid; HDHA: hydroxy-docosahexaenoic acid. Concentration is shown as ng/g tissue samples. ${ }^{*} p<0.05$ compared to control; ${ }^{\#} p<0.05$ and ${ }^{\# \#} p<$ 0.01 compared to ISO.

Table 7

Levels of non-enzymatic oxidized PUFA products measured in rat plasma ( $\mathrm{ng} / \mathrm{ml})$.

\begin{tabular}{|c|c|c|c|c|c|c|}
\hline & Control & FS & FSO & ISO & $\mathrm{FS}+\mathrm{ISO}$ & FSO + ISO \\
\hline \multicolumn{7}{|c|}{ Non-enzymatic oxidized lipid products from $A A$} \\
\hline $5-F_{2 t}$-IsoP & $15.84 \pm 9.51$ & $5.55 \pm 5.51$ & $6.98 \pm 0.97$ & $46.39 \pm 8.96^{* *}$ & $11.97 \pm 6.97^{\# \# \#}$ & $13.35 \pm 3.32^{\# \# \#}$ \\
\hline $15-F_{2 t}$-IsoP & $36.85 \pm 20.46$ & $9.60 \pm 5.45$ & $17.86 \pm 3.22$ & $108.54 \pm 14.56^{* *}$ & $27.22 \pm 14.76^{\# \#}$ & $33.71 \pm 11.22^{\# \# \#}$ \\
\hline \multicolumn{7}{|c|}{ Non-enzymatic oxidized lipid products from ALA } \\
\hline 9-D $1 \mathrm{t}^{-P h y t o P}$ & $9.23 \pm 4.24$ & $33.44 \pm 3.12^{* * * *}$ & $30.14 \pm 6.13 * *$ & $5.71 \pm 3.21$ & $19.34 \pm 4.73^{\# \#}$ & $19.61 \pm 6.36^{\# \#}$ \\
\hline 9-F $1 \mathrm{t}^{-P h y t o P}$ & $8.84 \pm 1.79$ & $25.61 \pm 4.99 * * *$ & $32.30 \pm 7.80^{* *}$ & $10.72 \pm 3.52$ & $32.81 \pm 8.04^{\# \#}$ & $34.68 \pm 8.11^{\# \# \#}$ \\
\hline $16-F_{1 t^{-P h y t o P}}$ & $6.39 \pm 2.07$ & $29.80 \pm 4.25^{* * * *}$ & $28.47 \pm 8.58 * *$ & $8.60 \pm 3.27$ & $22.75 \pm 4.58^{\# \#}$ & $26.38 \pm 7.42^{\# \#}$ \\
\hline 9- $\mathrm{L}_{1}-\mathrm{PhytoP}$ & $5.60 \pm 2.37$ & $24.63 \pm 1.93^{* * * *}$ & $16.38 \pm 4.19^{* *}$ & $5.84 \pm 1.28$ & $22.18 \pm 3.83^{\# \# \#}$ & $22.34 \pm 4.30^{\# \# \#}$ \\
\hline 16-B 1 -PhytoP & $5.44 \pm 2.23$ & $33.63 \pm 4.90^{* * * *}$ & $24.94 \pm 7.91 * *$ & $1.91 \pm 0.90$ & $27.79 \pm 7.68^{\# \# \#}$ & $29.23 \pm 3.85^{\# \# \# \#}$ \\
\hline 16(RS)-13-ST- $\Delta^{14}-9-$ PhytoF & $0.77 \pm 0.25$ & $1.48 \pm 0.12^{* *}$ & $1.45 \pm 0.28^{*}$ & $0.92 \pm 0.32$ & $2.54 \pm 0.43^{\# \# \#}$ & $5.37 \pm 3.55^{\#}$ \\
\hline 16-(RS)-9-epi-ST- $\Delta^{14}-10-$ PhytoF & $3.64 \pm 1.34$ & $6.06 \pm 1.11^{*}$ & $5.55 \pm 0.65^{*}$ & $2.62 \pm 1.62$ & $8.24 \pm 1.40^{\# \#}$ & $10.60 \pm 2.30^{\# \#}$ \\
\hline \multicolumn{7}{|c|}{ Non-enzymatic oxidized lipid products from EPA } \\
\hline $5-F_{3 t}-$ IsoP & $4.13 \pm 3.39$ & $9.20 \pm 4.64$ & $9.68 \pm 3.65$ & $5.90 \pm 2.23$ & $5.27 \pm 1.94$ & $6.05 \pm 2.97$ \\
\hline 8-F Ft-IsoP & $0.74 \pm 0.63$ & $3.03 \pm 2.27$ & $1.77 \pm 1.12$ & $0.81 \pm 0.82$ & $1.32 \pm 0.72$ & $1.43 \pm 0.63$ \\
\hline \multicolumn{7}{|c|}{ Non-enzymatic oxidized lipid products from DHA } \\
\hline $4-F_{4 t}-$ NeuroP & $5.84 \pm 1.12$ & $53.00 \pm 21.00^{* *}$ & $43.94 \pm 11.19^{* * *}$ & $4.65 \pm 1.64$ & $18.79 \pm 6.14^{\# \#}$ & $17.14 \pm 9.35^{\#}$ \\
\hline $10-\mathrm{F}_{4 \mathrm{t}}$-NeuroP & $0.21 \pm 0.09$ & $2.55 \pm 1.07^{* *}$ & $1.70 \pm 1.19^{*}$ & $0.39 \pm 0.17$ & $5.05 \pm 3.40^{\#}$ & $1.65 \pm 0.31^{\# \# \#}$ \\
\hline 8-HDHA & $12.14 \pm 1.65$ & $15.03 \pm 0.38^{*}$ & $13.26 \pm 5.25$ & $9.41 \pm 2.51$ & $11.25 \pm 3.29$ & $10.88 \pm 2.98$ \\
\hline
\end{tabular}

Data are presented as mean \pm S.D. $(n=4)$. ISO: isoproterenol was treated to the rats after supplementation period; FS: flaxseed; FSO: flaxseed oil. HDHA: hydroxydocosahexaenoic acid; IsoP: isoprostane; PhytoP: phytoprostane; PhytoF: phytofuran; NeuroP: neuroprostane. ${ }^{*} p<0.05,{ }^{* *} p<0.01,{ }^{* * *} p<0.001$ and ${ }^{* * * *} p<0.0001$ compared to control; ${ }^{\#} p<0.05,{ }^{\# \#} p<0.01$, ${ }^{\# \# \# ~}<0.001$ and ${ }^{\# \# \# \# ~} p<0.0001$ compared to ISO.

ALA from the diet will increase the conversion of ALA to EPA by $\Delta^{6}$ desaturase, therefore the availability is limited for the conversion of EPA to DHA [38]. Moreover, Gibson et al. reported DHA level can be improved by ALA enriched diet, if the diet should consist of low PUFAs that would take up less than $3 \%$ of the total energy intake. Otherwise, the conversion of EPA to DHA becomes inhibited by high levels of ALA [39]. Nonetheless, the energy intake from PUFAs is approximately $8-10 \%$ for each diet used in this study therefore, it is unlikely the diets were able to enhance DHA levels in the rats. In addition, a large reduction of all PUFA were observed in MI rats compared to control. It is probable that PUFAs are being metabolized to different pathways and by large, oxidized by the free radical/ROS reactions initiated by ISO.

Putting together, the measurements of oxidized PUFA products and the inflammatory genes strongly showed ALA-diets aids heart tissues to maintain homeostasis after MI by resolving inflammation at molecular level, by down-regulating gene encoding pro-inflammatory cytokine proteins and through cellular level, by lowering the production of proinflammatory LOX-mediated HETEs from AA and increase the production of anti-inflammatory LOX-mediated HDHA from DHA in the cells. Furthermore, it was noticed that the effect of reduced LOX-mediated HETEs and elevated LOX-mediated HDHA by the diets were similar; it is also emphasized that the level of ALA in the diets are alike.

However, it appears that the reduction of IL- $1 \beta$ and IL- 6 expressions were stronger in MI rats fed with FS diets. It is possibly due to the difference in the nutritional value of FS and FSO. FS is rich in bioactive phenolic acids. There is $800-1000 \mathrm{mg}$ of phenolic acids in $100 \mathrm{~g}$ of flaxseed [40]. Morever, some phenolic acids including p-coumaric acid, chlorogenic acid, gallic acid, sinapic acid, protocatechuic acid and p-hydroxybenzoic acid are found to be remained in defatted flaxseed meal after flaxseed oil removal [41]. This is probably the reason why in our Folin-Ciocalteu assay, the total phenolic content of flaxseed oil was significantly lower compared to flaxseed. Further, defatted flaxseed meal has high levels of plant lignans (a polyphenol) and dietary fiber which are missing in flaxseed oil. Plant lignans can scavenge ROS and act as an antioxidant, and potentially reduce inflammation. Studies discovered that flax lignans are one of the major contributors for the atheroprotective effects of flaxseed $[42,43]$. Animal studies showed that flax lignans suppressed the progression of atherosclerosis and reduced blood pressure through anti-oxidative actions $[44,45]$. A recent human study investigated the effect of flax lignans on cardiovascular risk factors and found that only high-lignan flaxseed diet but not low-lignan flaxseed diet reduced the concentration of plasma oxidized LDL, even though both flaxseed diet had the same amount of ALA [46]. This may be the reason for FS diet to have stronger cardioprotective than flaxseed oil diet in this study.

Lipid products of non-enzymatic oxidation of PUFAs in the liver and heart tissues, and plasma were also altered by ALA-diets. It was found that ISO-induced MI increased non-enzymatic oxidized products from 
A

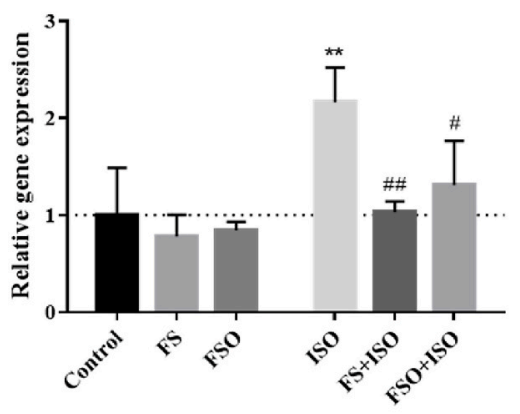

C

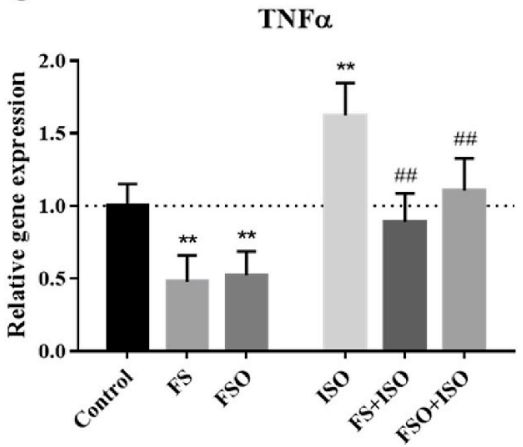

B

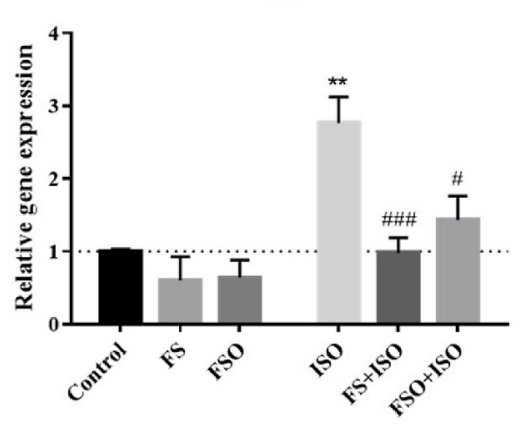

D

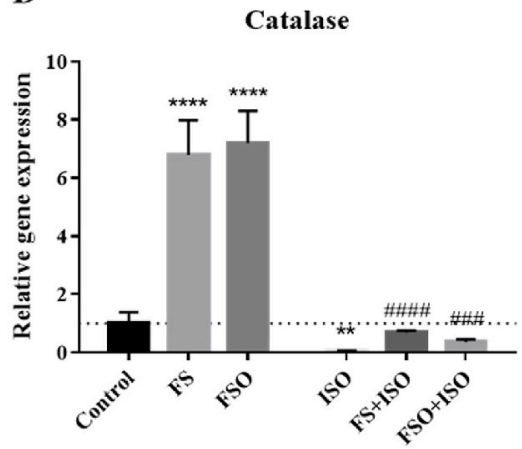

Fig. 7. Gene expressions of IL1 $\beta$, IL6, TNF $\alpha$ and catalase in heart tissues.

Data were normalized to $18 \mathrm{~S}$ ribosomal RNA and control tissues. Value are presented as mean \pm S.D. (n $=4$ ). ISO: isoproterenol was treated to the rats after supplementation period; FS: flaxseed; FSO: flaxseed oil. ${ }^{* *} p<0.01$ and ${ }^{*} * * * p<0.0001$ compared to control; $\# p<0.05, \# \# \mathrm{p}<0.01, \# \# \# \mathrm{p}<0.001$ and $\# \# \#$ \# $<0.0001$ compared to ISO.
AA including $5-\mathrm{F}_{2 \mathrm{t}}-\mathrm{IsoP}$ and $15-\mathrm{F}_{2 \mathrm{t}}-\mathrm{IsoP}$ in all tissues and plasma due to oxidative stress by ISO during MI. These products are known as in vivo oxidative stress biomarkers [47] where both were reduced in MI rats pretreated with ALA-diets in the liver and heart tissues, and plasma indicating that FS and FSO are free radical scavenging and thus as explained, hold antioxidant properties.

The gene expression of CAT, an antioxidant enzyme showed to be reduced significantly by ISO-induced MI in the heart tissues, indicating that the antioxidant function was greatly affected by the injury. Yu et al. reported that ALA intake could arrest the reduction of myocardial catalase in the heart under myocardial injury [35] which was also observed in this study where both ALA-diets prevented the reduction of catalase gene expression in the MI heart tissue. It is noted that ALA-diets also up-regulated the gene expression of CAT in the heart tissues without MI induction showing that the antioxidant capacity was indeed boosted by ALA supplementation.

Notably, ALA-diets elevated PhytoPs and PhtyoFs in both liver and heart tissues, and plasma. Referring to the levels of PhytoPs and PhytoFs, we found that total PhytoPs and PhytoFs to be significantly higher in FS than FSO at same concentration of ALA in the diets; however, these levels are minute (pg/g of ALA) compared to the concentrations observed in the tissues ( $\mathrm{ng} / \mathrm{g}$ of tissue) and plasma ( $\mathrm{ng} / \mathrm{ml}$ ) in the study. Hence, we hypothesize that the PhytoPs and PhytoFs levels in the tissues and plasma are not achievable by the diet given to the rodents and instead, are released through in vivo autooxidation process of the ALA consumed.

The role of PhytoPs and PhtyoFs in the liver and heart tissues, and in circulation is still unclear since no reports are available indicating its contribution to cardioprotection. Nonetheless, we showed both PhytoPs and PhytoFs to remain elevated even in MI event. Previous reports suggest that PhytoPs have potential antioxidative properties [14,15]. Moreover, $\mathrm{F}_{4 \mathrm{t}}$-NeuroPs were inhibited by ISO but pretreatment with ALA-diets resisted this inhibition, where $4-\mathrm{F}_{4 \mathrm{t}}$-NeuroP was particularly elevated in the heart tissues and plasma. Insofar, it is known the activation of $\mathrm{F}_{4}$-NeuroPs is related to cardioprotection after $\mathrm{MI}$ and protect ischemic injury $[48,49]$. The purpose of this elevation is unknown, but it is postulated to mediate HDHA for anti-inflammatory responses. Such observation was found in the brain of rodents when infused with 4- $\mathrm{F}_{4 \mathrm{t}}$-NeuroP [50]. In the current study, we showed the activation of HDHA was more prominent in the injured heart tissues than the liver. Furthermore, the vasoconstrictive property of $15-\mathrm{F}_{2 \mathrm{t}}$-IsoP [51] was potentially reduced by ALA-diets when ISO was introduced to the rodents. and perhaps it was counteracted by the reduction of AA, the precursor of $15-\mathrm{F}_{2 \mathrm{t}}$-IsoP after ALA-diets consumption. Put together, the increase in $\mathrm{F}_{4}$-NeuroP, PhytoPs and PhytoFs in the heart tissue of rats fed with ALA-diets potentially modulated reactive oxygen species released by MI as a mean to prevent the oxidative stress and possibly inflammation $[14,15,50]$. As a result, PUFA such as DHA did not oxidize to an extreme to generate toxic aldehydes such as malondialdehyde (MDA), 4-hydroxy-2-hexenal (HHE) and 4-hydroxy-2-nonenal (HNE), that may have caused even greater damage to the heart tissues [52]. This persistent action may be a potential hallmark in cardioprotection.

\section{Conclusion}

Altogether, in this study n-3 PUFA (ALA) from plant-based diets provided cardiac protection as like those (EPA and DHA) from marinebased diets. For the first time, we also displayed the mediation of oxidized PUFA products by ALA-diet, notably $4-\mathrm{F}_{4 \mathrm{t}}-\mathrm{NeuroP}$ and HDHA derived from DHA. Furthermore, PhytoPs and PhytoFs appeared to have potential regulatory role in cardiac function. However, it is also noted, plant-based food rich in n-3 PUFA like flaxseed contain high levels of functional phenolic compounds which may have added to the cardioprotective effect.

\section{Appendix A. Supplementary data}

Supplementary data to this article can be found online at https://doi. org/10.1016/j.freeradbiomed.2020.11.025. 


\section{References}

[1] F.B. Hu, L. Bronner, W.C. Willett, M.J. Stampfer, K.M. Rexrode, C.M. Albert, D. Hunter, J.E. Manson, Fish and omega-3 fatty acid intake and risk of coronary heart disease in women, J. Am. Med. Assoc. 287 (14) (2002) 1815-1821.

[2] R.N. Lemaitre, I.B. King, D. Mozaffarian, L.H. Kuller, R.P. Tracy, D.S. Siscovick, n-3 Polyunsaturated fatty acids, fatal ischemic heart disease, and nonfatal myocardia infarction in older adults: the Cardiovascular Health Study, Am. J. Clin. Nutr. 77 (2) (2003) 319-325.

[3] J. Goodfellow, M.F. Bellamy, M.W. Ramsey, C.J. Jones, M.J. Lewis, Dietary supplementation with marine omega-3 fatty acids improve systemic large artery endothelial function in subjects with hypercholesterolemia, J. Am. Coll. Cardiol. 35 (2) (2000) 265-270.

[4] J.H. O'Keefe Jr., H. Abuissa, A. Sastre, D.M. Steinhaus, W.S. Harris, Effects of omega-3 fatty acids on resting heart rate, heart rate recovery after exercise, and heart rate variability in men with healed myocardial infarctions and depressed ejection fractions, Am. J. Cardiol. 97 (8) (2006) 1127-1130.

[5] P.G. Swann, C.A. Parent, M. Croset, P. Fonlupt, M. Lagarde, D.L. Venton, G.C. Le Breton, Enrichment of platelet phospholipids with eicosapentaenoic acid and docosahexaenoic acid inhibits thromboxane A2/prostaglandin $\mathrm{H} 2$ receptor binding and function, J. Biol. Chem. 265 (35) (1990) 21692-21697.

[6] J.G. Robinson, N.J. Stone, Antiatherosclerotic and antithrombotic effects of omega 3 fatty acids, Am. J. Cardiol. 98 (4A) (2006) 39i-49i.

[7] P.L. McLennan, Myocardial membrane fatty acids and the antiarrhythmic actions of dietary fish oil in animal models, Lipids 36 (Suppl) (2001) S111-S114.

[8] S. Rajaram, Health benefits of plant-derived alpha-linolenic acid, Am. J. Clin. Nutr. 100 (Suppl 1) (2014), 443S-8S.

[9] S.K. Gebauer, T.L. Psota, W.S. Harris, P.M. Kris-Etherton, n-3 fatty acid dietary recommendations and food sources to achieve essentiality and cardiovascular benefits, Am. J. Clin. Nutr. 83 (6 Suppl) (2006) 1526S-1535S.

[10] C. Degirolamo, K.L. Kelley, M.D. Wilson, L.L. Rudel, Dietary n-3 LCPUFA from fis oil but not alpha-linolenic acid-derived LCPUFA confers atheroprotection in mice, J. Lipid Res. 51 (7) (2010) 1897-1905.

[11] S. Mueller, B. Hilbert, K. Dueckershoff, T. Roitsch, M. Krischke, M.J. Mueller, S. Berger, General detoxification and stress responses are mediated by oxidized lipids through TGA transcription factors in Arabidopsis, Plant Cell 20 (3) (2008) $768-785$.

[12] C. Loeffler, S. Berger, A. Guy, T. Durand, G. Bringmann, M. Dreyer, U. von Rad, J. Durner, M.J. Mueller, B1-phytoprostanes trigger plant defense and detoxification responses, Plant Physiol. 137 (1) (2005) 328-340.

[13] A.E. Barden, K.D. Croft, T. Durand, A. Guy, M.J. Mueller, T.A. Mori, Flaxseed oil supplementation increases plasma F1-phytoprostanes in healthy men, J. Nutr. 139 (10) (2009) 1890-1895.

[14] S. Gilles, V. Mariani, M. Bryce, M.J. Mueller, J. Ring, T. Jakob, S. Pastore, H. Behrendt, C. Traidl-Hoffmann, Pollen-derived E1-phytoprostanes signal via PPAR-gamma and NF-kappaB-dependent mechanisms, J. Immunol. 182 (11) (2009) 6653-6658.

[15] L. Minghetti, R. Salvi, M. Lavinia Salvatori, M.A. Ajmone-Cat, C. De Nuccio, S. Visentin, V. Bultel-Ponce, C. Oger, A. Guy, J.M. Galano, A. Greco, A. Bernardo, T. Durand, Nonenzymatic oxygenated metabolites of alpha-linolenic acid B1- and L1-phytoprostanes protect immature neurons from oxidant injury and promote differentiation of oligodendrocyte progenitors through PPAR-gamma activation, Free Radic. Biol. Med. 73 (2014) 41-50.

[16] N. Gonzalez Roldan, R. Engel, S. Dupow, K. Jakob, F. Koops, Z. Orinska, C. Vigor C. Oger, J.M. Galano, T. Durand, U. Jappe, K.A. Duda, Lipid mediators from timothy grass pollen contribute to the effector phase of allergy and prime dendritic cells for glycolipid presentation, Front. Immunol. 10 (2019) 974.

[17] C. Hall 3rd, M.C. Tulbek, Y. Xu, Flaxseed, Adv. Food Nutr. Res. 51 (2006) 1-97.

18] P. Collins, C.G. Billings, Isoprenaline-induced changes in regional myocardial perfusion in the pathogenesis of myocardial necrosis, Br. J. Exp. Pathol. 57 (6) (1976) 637-644.

[19] G. Rona, Catecholamine cardiotoxicity, J. Mol. Cell. Cardiol. 17 (4) (1985) 291-306.

[20] S. Ojha, S. Goyal, C. Sharma, S. Arora, S. Kumari, D.S. Arya, Cardioprotective effec of lycopene against isoproterenol-induced myocardial infarction in rats, Hum. Exp. Toxicol. 32 (5) (2013) 492-503.

[21] R.O. Lobo, C.K. Shenoy, Myocardial potency of Bio-tea against Isoproterenol induced myocardial damage in rats, J. Food Sci. Technol. 52 (7) (2015) 4491-4498.

[22] S.S. Mohamed, L.A. Ahmed, W.A. Attia, M.M. Khattab, Nicorandil enhances th efficacy of mesenchymal stem cell therapy in isoproterenol-induced heart failure in rats, Biochem. Pharmacol. 98 (3) (2015) 403-411.

[23] T. Balazs, G. Johnson, X. Joseph, S. Ehrreich, S. Bloom, Sensitivity and resistance of the myocardium to the toxicity of isoproterenol in rats, Adv. Exp. Med. Biol. 161 (1983) 563-577.

[24] D.M. Luzia, N. Jorge, Fatty acids profile and alteration of lemon seeds extract (Citrus limon) added to soybean oil under thermoxidation, J. Food Sci. Technol. 50 (5) (2013) 965-971.

[25] E.A. Ainsworth, K.M. Gillespie, Estimation of total phenolic content and other oxidation substrates in plant tissues using Folin-Ciocalteu reagent, Nat. Protoc. 2 (4) (2007) 875-877.

[26] J. Folch, M. Lees, G.H. Sloane Stanley, A simple method for the isolation and purification of total lipides from animal tissues, J. Biol. Chem. 226 (1) (1957) 497-509.
[27] Y.Y. Lee, J.C. Lee, LC-MS/MS analysis of lipid oxidation products in blood and tissue samples, Methods Mol. Biol. 1730 (2018) 83-92.

[28] Y.Y. Lee, C. Crauste, H. Wang, H.H. Leung, J. Vercauteren, J.M. Galano, C. Oger, T. Durand, J.M. Wan, J.C. Lee, Extra virgin olive oil reduced polyunsaturated fatty acid and cholesterol oxidation in rodent liver: is this accounted for hydroxytyrosolfatty acid conjugation? Chem. Res. Toxicol. 29 (10) (2016) 1689-1698.

[29] A. Dupuy, P. Le Faouder, C. Vigor, C. Oger, J.M. Galano, C. Dray, J.C. Lee, P. Valet, C. Gladine, T. Durand, J. Bertrand-Michel, Simultaneous quantitative profiling of 20 isoprostanoids from omega- 3 and omega- 6 polyunsaturated fatty acids by LCMS/MS in various biological samples, Anal. Chim. Acta 921 (2016) 46-58.

[30] Y.Y. Lee, C.K. Wong, C. Oger, T. Durand, J.M. Galano, J.C. Lee, Prenatal exposure to the contaminant perfluorooctane sulfonate elevates lipid peroxidation during mouse fetal development but not in the pregnant dam, Free Radic. Res. 49 (8) (2015) 1015-1025.

[31] M. Ishihara, I. Inoue, T. Kawagoe, Y. Shimatani, S. Kurisu, K. Nishioka, T. Umemura, S. Nakamura, M. Yoshida, Impact of acute hyperglycemia on left ventricular function after reperfusion therapy in patients with a first anterior wall acute myocardial infarction, Am. Heart J. 146 (4) (2003) 674-678.

[32] A. Derbali, K. Mnafgui, M. Affes, F. Derbali, R. Hajji, N. Gharsallah, N. Allouche, A. El Feki, Cardioprotective effect of linseed oil against isoproterenol-induced myocardial infarction in Wistar rats: a biochemical and electrocardiographic study, J. Physiol. Biochem. 71 (2) (2015) 281-288.

[33] J.P. Higgins, J.A. Higgins, Elevation of cardiac troponin I indicates more than myocardial ischemia, Clin. Invest. Med. 26 (3) (2003) 133-147.

[34] J.H. Ladenson, A personal history of markers of myocyte injury [myocardial infarction], Clin. Chim. Acta 381 (1) (2007) 3-8.

[35] X. Yu, L. Cui, Z. Zhang, Q. Zhao, S. Li, alpha-Linolenic acid attenuates doxorubicininduced cardiotoxicity in rats through suppression of oxidative stress and apoptosis, Acta Biochim. Biophys. Sin. 45 (10) (2013) 817-826.

[36] H. Poudyal, S.K. Panchal, J. Waanders, L. Ward, L. Brown, Lipid redistribution by alpha-linolenic acid-rich chia seed inhibits stearoyl-CoA desaturase-1 and induces cardiac and hepatic protection in diet-induced obese rats, J. Nutr. Biochem. 23 (2) (2012) 153-162.

[37] G.C. Burdge, P.C. Calder, Conversion of alpha-linolenic acid to longer-chain polyunsaturated fatty acids in human adults, Reprod. Nutr. Dev. 45 (5) (2005) 581-597.

[38] H. Sprecher, O. Chen, F.Q. Yin, Regulation of the biosynthesis of 22:5n-6 and 22: 6n-3: a complex intracellular process, Lipids 34 (Suppl) (1999) S153-S156.

[39] R.A. Gibson, M.A. Neumann, E.L. Lien, K.A. Boyd, W.C. Tu, Docosahexaenoic acid synthesis from alpha-linolenic acid is inhibited by diets high in polyunsaturated fatty acids, Prostaglandins Leukot. Essent. Fatty Acids 88 (1) (2013) 139-146.

[40] F. Shahidi, M. Naczk, Phenolics in Food and Nutraceuticals, CRC Press, 2003.

[41] S. Charlet, L. Bensaddek, S. Raynaud, F. Gillet, F. Mesnard, M.-A. Fliniaux, An HPLC procedure for the quantification of anhydrosecoisolariciresinol. Application to the evaluation of flax lignan content, Plant Physiol. Biochem. 40 (3) (2002) 225-229.

[42] K. Prasad, A. Jadhav, Prevention and treatment of atherosclerosis with flaxseedderived compound secoisolariciresinol diglucoside, Curr. Pharmaceut. Des. 22 (2) (2016) 214-220.

[43] M. Imran, N. Ahmad, F.M. Anjum, M.K. Khan, Z. Mushtaq, M. Nadeem, S. Hussain, Potential protective properties of flax lignan secoisolariciresinol diglucoside, Nutr. J. 14 (2015) 71.

[44] S.H. Sawant, S.L. Bodhankar, Flax lignan concentrate reverses alterations in blood pressure, left ventricular functions, lipid profile and antioxidant status in DOCAsalt induced renal hypertension in rats, Ren. Fail. 38 (3) (2016) 411-423.

[45] A.A. Zanwar, M.V. Hegde, S.L. Bodhankar, Cardioprotective activity of flax lignan concentrate extracted from seeds of Linum usitatissimum in isoprenalin induced myocardial necrosis in rats, Interdiscipl. Toxicol. 4 (2) (2011) 90-97.

[46] R.U. Almario, S.E. Karakas, Lignan content of the flaxseed influences its biological effects in healthy men and women, J. Am. Coll. Nutr. 32 (3) (2013) 194-199.

[47] J.M. Galano, E. Mas, A. Barden, T.A. Mori, C. Signorini, C. De Felice, A. Barrett, C. Opere, E. Pinot, E. Schwedhelm, R. Benndorf, J. Roy, J.Y. Le Guennec, C. Oger, T. Durand, Isoprostanes and neuroprostanes: total synthesis, biological activity and biomarkers of oxidative stress in humans, Prostag. Other Lipid Mediat. 107 (2013) 95-102.

[48] J. Roy, J. Fauconnier, C. Oger, C. Farah, C. Angebault-Prouteau, J. Thireau, P. Bideaux, V. Scheuermann, V. Bultel-Ponce, M. Demion, J.M. Galano, T. Durand, J.C. Lee, J.Y. Le Guennec, Non-enzymatic oxidized metabolite of DHA, 4(RS)-4-F4tneuroprostane protects the heart against reperfusion injury, Free Radic. Biol. Med. 102 (2017) 229-239.

[49] J. Roy, C. Oger, J. Thireau, J. Roussel, O. Mercier-Touzet, D. Faure, E. Pinot, C. Farah, D.F. Taber, J.P. Cristol, J.C. Lee, A. Lacampagne, J.M. Galano, T. Durand, J.Y. Le Guennec, Nonenzymatic lipid mediators, neuroprostanes, exert the antiarrhythmic properties of docosahexaenoic acid, Free Radic. Biol. Med. 86 (2015) 269-278.

[50] Y.Y. Lee, J.M. Galano, H.H. Leung, L. Balas, C. Oger, T. Durand, J.C. Lee, Nonenzymatic oxygenated metabolite of docosahexaenoic acid, 4(RS)-4-F4t -neuroprostane, acts as a bioactive lipid molecule in neuronal cells, FEBS Lett. 594 (11) (2020) 1797-1808.

[51] J.L. Cracowski, P. Devillier, T. Durand, F. Stanke-Labesque, G. Bessard, Vascular biology of the isoprostanes, J. Vasc. Res. 38 (2) (2001) 93-103.

[52] H. Esterbauer, R.J. Schaur, H. Zollner, Chemistry and biochemistry of 4-hydroxynonenal, malonaldehyde and related aldehydes, Free Radic. Biol. Med. 11 (1) (1991) 81-128. 